Aus der Urologischen Klinik und Poliklinik der Technischen Universität München

Klinikum rechts der Isar

Direktor: Univ. Prof. Dr. med. R. Hartung

\title{
DIE TRANSURETHRALE ELEKTRORESEKTION DER PROSTATA (TURP)
}

\section{LANGZEITERGEBNISSE NACH TURP AM PATIENTENGUT DER \\ UROLOGISCHEN KLINIK UND POLIKLINIK DER TECHNISCHEN UNIVERSITÄT MÜNCHEN}

Dissertation

zum Erwerb des Doktorgrades der Medizin an der Medizinischen Fakultät der Technischen Universität zu München

Jürgen Böhm

Straubing, 2004 
Urologische Klinik und Poliklinik

der Technischen Universität München

Klinikum rechts der Isar

(Direktor: Univ.-Prof. Dr. R. Hartung)

\begin{abstract}
DIE TRANSURETHRALE ELEKTRORESEKTION DER PROSTATA (TURP)
\end{abstract}

\title{
LANGZEITERGEBNISSE NACH TURP AM PATIENTENGUT DER UROLOGISCHEN KLINIK UND POLIKLINIK DER TECHNISCHEN UNIVERISITÄT MÜNCHEN
}

Jürgen Böhm

Vollständiger Abdruck der von der Fakultät für Medizin der Technischen Universität München zur Erlangung des akademischen Grades eines Doktors der Medizin genehmigten Dissertation.

Vorsitzender: $\quad$ Univ.-Prof. Dr. D. Neumeier

Prüfer der Dissertation: 1. apl. Prof. Dr. H. Leyh

2. Univ.-Prof. .Dr. R. Hartung

Die Dissertation wurde am 22.09.2004 bei der Technischen Universität München eingereicht und durch die Fakultät für Medizin am 17.11.2004 angenommen. 


\section{GLIEDERUNG:}

\section{EINLEITUNG -}

Das Krankheitsbild der benignenProstatahyperplasie.................. 5

1.1. Epidemiologie, Anatomie, Histologie...................................... 5

1.2. Ätiologie/Pathogenese......................................................... 7

1.3. Symptomatik - Klinisches Bild und Diagnostik......................... 11

2. BESCHREIBUNG DER TURP........................................ 14

3. THERAPIEALTERNATIVEN ................................................ 15

3.1. Pharmakologische Ansätze................................................... 15

3.1.1. Hormontherapie................................................................ 15

3.1.2. $\alpha 1$-Adrenorezeptorantagonisten ( $\alpha$-Blocker)......................... 17

3.1.3. Phytotherapie.................................................................. 18

3.2. Instrumentelle Therapie...................................................... 19

3.2.1. Wärmetherapie............................................................... 19

3.2.1.1. Hyperthermie........................................................................... 19

3.2.1.2. Thermotherapie - TUMT ......................................................... 19

3.2.1.3. Transurethrale Nadelablation - TUNA....................................... 19

3.2.1.4. Fokussierter Hochfrequenzultraschall - HIFU........................... 20

3.2.2. Kryotherapie................................................................... 20

3.2.3. Mechanische Therapieansätze................................................. 20

3.2.3.1. Ballondilatation...................................................................... 20

3.2.3.2. Intraprostatische Implantate................................................... 20

3.2.4. Lasertherapie.................................................................. 21

3.2.4.1. Transurethrale Laserkoagulation der Prostata............................. 21

3.2.4.2. Interstitielle Laserkoagulation der Prostata - ILK....................... 21

3.2.5. Sonstige invasive Verfahren................................................... 22

3.2.5.1. Transurethrale Inzision der Prostata - TUIP............................. 22

3.2.5.2. Transurethrale Vaporisation der Prostata - TUVP...................... 22

3.2.5.3. Offene Prostatektomie................................................................ 23

3.2.6. Ablativ operative Verfahren in klinischer Erprobung................ 23

3.2.6.1. Transurethrale Rotoresektion der Prostata................................ 23

3.2.6.2. „Koagulierendes intermittierendes Schneiden“ “........................ 23 (KIS cocut BMP) 
4. ZIELE DER STUDIE............................................................. 25

5. MATERIAL UND METHODIK ………………………............ 26

6. ERGEBNISSE ................................................................... 27

6.1. Präoperative Situation................................................................ 27

6.1.1. Vor- und Begleiterkrankungen.................................................. 27

6.1.2. Urologische Vorerkrankungen .............................................. 28

6.1.3. Vorgeschaltete konservative Therapie........................................ 28

6.1.4. Urologische Voroperationen/Eingriffe....................................... 28

6.1.5. Symptomatik....................................................................... 29

6.1.6. Miktionsfrequenz (präoperativ) ................................................... $\quad 30$

6.1.7. Lebensqualität....................................................................... 30

6.2. Präoperative Diagnostik.............................................................. 31

6.2.1. Digital-rektale Untersuchung (DRU)........................................ 31

6.2.2. Laborchemische Parameter........................................................ 32

6.2.2.1. Urinuntersuchungen.............................................................. 32

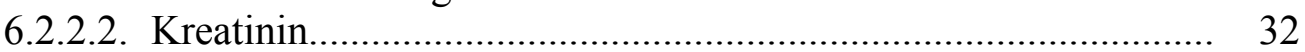

6.2.2.3. Prostata spezifisches Antigen (PSA)........................................ 32

6.2.3. Sonographie........................................................................ 33

6.2.3.1. Sonographie der Nieren............................................................ 33

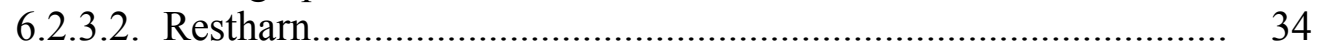

6.2.3.3. Transrektaler Ultraschall (TRUS)............................................. 34

6.2.3.4. Adenomgewicht.................................................................... 35

6.2.4. Invasive Diagnostik................................................................. 35

6.2.5. Ausscheidungsurogramm........................................................ 36

6.2.6. Zystoskopie ....................................................................... 36

6.2.7. Indikation......................................................................... 37

6.2.8. Präoperative Diagnose............................................................. 38

6.3. Perioperativer Verlauf.................................................................. 38

6.3.1. Operations-Zeit................................................................... 38

6.3.2 Anästhesieverfahren............................................................... 39

6.3.3. Spülflüssigkeit........................................................................ $\quad 40$

6.3.4. Zusatzeingriffe....................................................................... 40 
6.3.5. Resektionsgewicht............................................................. 41

6.3.6. Histologischer Befund............................................................... 41

6.3.7. Dauerkatheter.................................................................... 42

6.3.8. Hämoglobinwerte und Bluttransfusionen................................... 42

6.3.9. Natrium-Wert...................................................................... 43

6.4. Komplikationen............................................................... 44

6.4.1. Intraoperative Komplikationen............................................... 44

6.4.2. Allgemeine Komplikationen................................................... 44

6.4.3. Frühkomplikationen.............................................................. 45

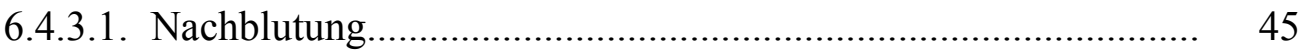

6.4.3.2. Restharnbildung und Harnverhalt............................................ 45

6.4.3.3. Nachresektion.......................................................... 46

6.4.3.4. Entzündungen..................................................................... 46

6.4.4. Spätkomplikationen............................................................... 46

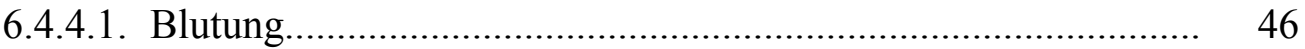

6.4.4.2. Blasenhalsenge und Harnröhrenstriktur................................... 47

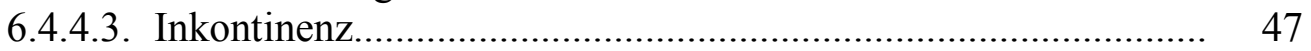

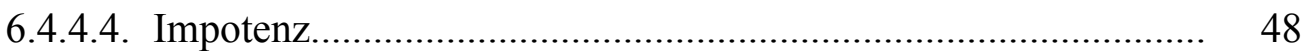

6.5. Nachsorge .......................................................................... 48

6.5.1. Miktionsfrequenz.................................................................. 48

6.5.2. Lebensqualität (postoperativ) ................................................ 49

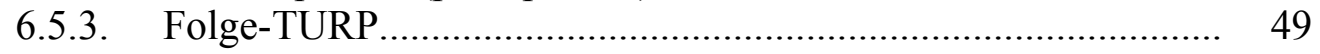

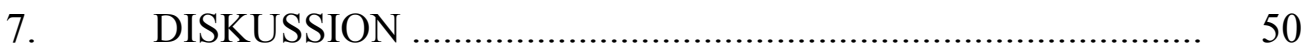

8. ZUSAMMENFASSUNG ................................................. 58

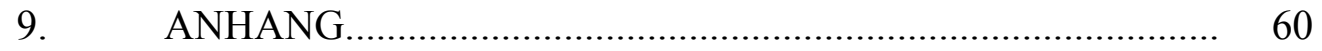

9.1. Fragebogen........................................................................ 60

9.2. Tabellen und Abbildungen................................................. 63

9.3. Literaturverzeichnis........................................................ 65 


\section{EINLEITUNG- \\ Das Krankheitsbild der benignen Prostatahyperplasie}

\subsection{Epidemiologie, Anatomie, Histologie}

Die benigne Prostatahyperplasie stellt eines der häufigsten Krankheitsbilder des alternden Mannes dar. Bei etwa der Hälfte der sechzigjährigen Männer ist bereits eine benigne Prostatahyperplasie histologisch nachweisbar, in der Altersgruppe über achtzig Jahren leiden sogar rund $90 \%$ an der Erkrankung, während bei Männern vor dem 30. Lebensjahr keine benigne Prostatahyperplasie zu finden ist (11), (16).

Die bei Geburt ca. 1-2 Gramm schwere Prostata (30) wächst unter Einfluss von 5 $\alpha$ Dihydrotestosteron $(5 \alpha$-DHT) bis zum Abschluss der Pubertät auf ihre normale Erwachsenengrösse von ca. 17-20 Gramm heran (28).

Morphologisch läßt sich an der Prostata ein zentraler und ein peripherer Anteil unterscheiden (siehe Abb. 1). In Form eines Kegels mit seiner Basis am Blasenhals und der Spitze über dem Colliculus seminalis schliesst die zentrale Zone die Pars prostatica urethrae und die beiden Ductus ejaculatorii ein. Dieser zentrale Bereich sowie die Übergangszonen - zwei kleine periurethrale Lappen, die histologisch nicht vom peripheren Bereich der Prostata zu unterscheiden sind - sind der Ausgangspunkt der benignen Prostatahyperplasie.

Den eigentlichen Drüsenanteil stellt die periphere Zone dar, welche bei Vergrösserung der Innenzone durch Druckatrophie zur sogenannten ,chirurgischen Kapsel“ umgeformt wird. In der Aussenzone finden auch die meisten Prostatacarcinome ihren Ursprung. 


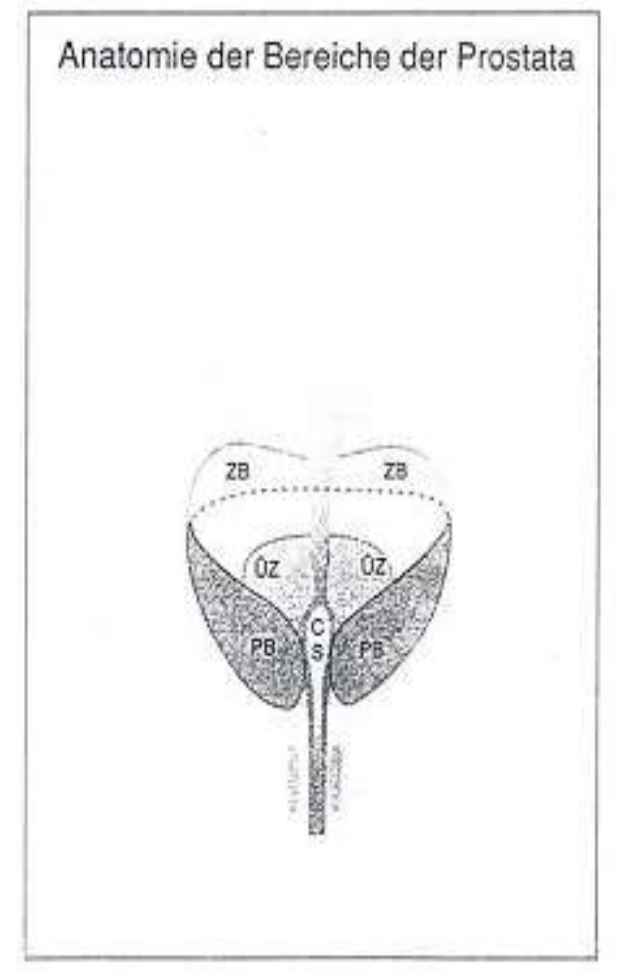

Antero-posteriore Ansicht des peripheren Bereichs (PB), des zentralen Bereichs (ZB) sowie der Übergangszone (ÜZ) und des (SB).

Colliculus seminalis (CS).

Abb. 1: Anatomie der Prostata nach Mc Neal (51)

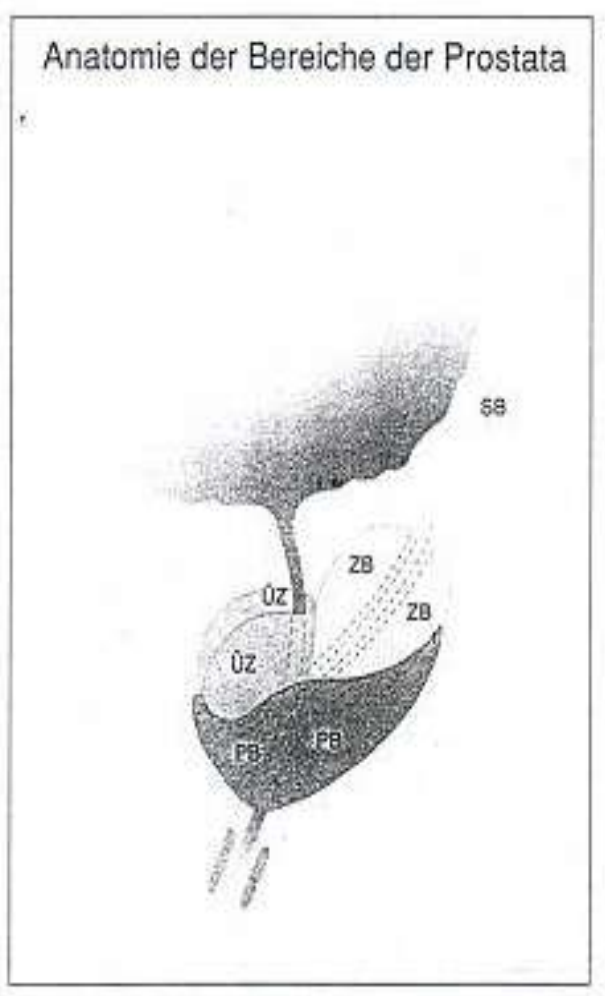

Sagittalansicht der peripheren und zentralen Bereiche sowie der Übergangszone und ihre Beziehung zu den Samenbläschen 
Die Vergrösserung eines Organs bzw. von Gewebe kann durch zwei unterschiedliche Mechanismen erfolgen. Geschieht dies durch Grössenzunahme der einzelnen Zellen (bei gleichbleibender Zellzahl), so spricht man von einer Hypertrophie. Bei der Hyperplasie dagegen liegt eine echte Neubildung von Zellen vor.

Histologisch liegt der benignen Prostatahyperplasie eine Proliferation vor allem des fibromuskulären (stromalen) Anteils der Prostata sowie (in geringerem Umfang) auch der glandulär/epithelialen Anteile zugrunde (40\% des zellulären Volumens der hyperplasierten Prostata bestehen aus glatter Muskulatur) (8).

Des weiteren finden sich typische Veränderungen in der Struktur der Ductus und Acini.

\section{2. Ätiologie/Pathogenese}

Durch die stetig zunehmende Überaltertung der Bevölkerung ergibt sich eine kontinuierliche Zunahme der behandlungsbedürftigen Männer. Laut Schätzungen belaufen sich die Kosten der benignen Prostatahyperplasie-assoziierten Behandlung weltweit auf mehrere Milliarden Dollar jährlich, wobei allein in Deutschland 1992 etwa 80.000 transurethrale Resektionen der Prostata (TURPs) durchgeführt und ca. 250 Mio. Mark für die medikamentöse Behandlung ausgegeben wurden (56).

Trotz dieses enormen Kostenfaktors konnte die Ätiologie der benignen Prostatahyperplasie noch nicht ganz geklärt werden; jedoch läßt die anfangs erwähnte altersspezifische Korrelation Rückschlüsse auf eine hormonbedingte Genese zu.

Der intraprostatische Androgenstoffwechsel ist durch ein komplexes Muster an metabolisierenden Enzymen charakterisiert (s. Abbildung), wobei im Zusammenhang mit der benignen Prostatahyperplasie vor allem der DHT-Metabolismus wichtig erscheint. 


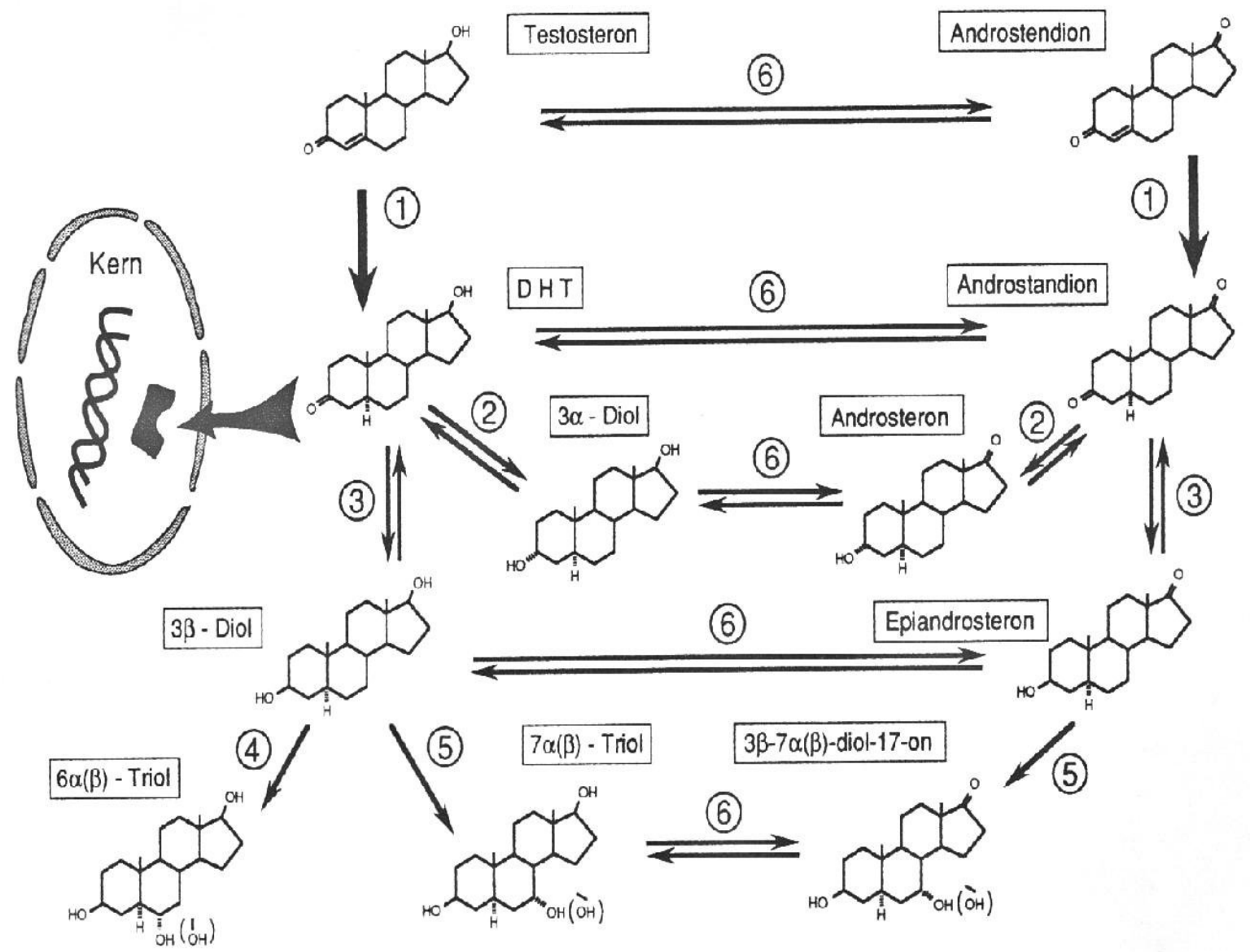

Abb. 2: Androgenstoffwechsel der menschlichen Prostatazelle (68)

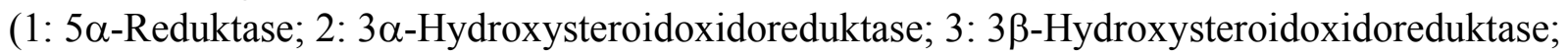
4: $6 \alpha(\beta)$-Hydroxylase; 5: $7 \alpha(\beta)$-Hydroxylase; 6: 17 $\beta$-Hydroxysteroidoxidoreduktase)

Die Ausgangssubstanz ist Testosteron, welches im Blut zu $98 \%$ vor allem an SerumHumanalbumin und das sexualhormonbindende Globulin (SHBG) gebunden ist. Die verbleibenden $2 \%$ an freiem Testosteron können in die Prostata gelangen und werden dort durch

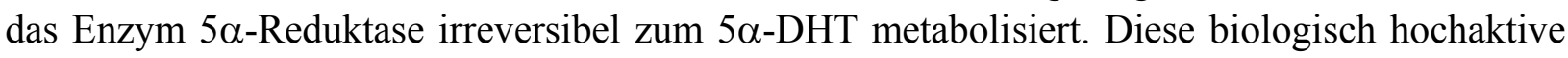
Form wird zum Teil an den Androgenrezeptor gebunden, welcher seinerseits (als DHTRezeptorkomplex) durch Bindung an androgenresponsive DNA-Elemente seine Wirkung (DNSSynthese und Zellreplikationen) entfaltet. Der restliche Anteil an DHT wird über verschiedene Wege in zum Teil biologisch nicht aktive Substanzen (Diole, Triole) verstoffwechselt. Für die DHT-Hypothese sprechen ein - wenn auch nicht übermäßig - überhöhter intrazellulärer DHTSpiegel in BPH-Gewebe sowie eine signifikante Erhöhung der 5 $\alpha$-Reduktase-Aktivität und der Dichte der Androgenrezeptoren. Beweisend für die Bedeutung von DHT für die Entwicklung einer benignen Prostatahyperplasie ist die Tatsache, daß beim männlichen Pseudohermaphroditismus (mit angeborenem Mangel an 5 $\alpha$-Reduktase) niemals eine benigne Prostatahyperplasie auftrat, die Prostata sich sogar nur klein oder rudimentär entwickelt (51), (60) 
Eine weitere Theorie zur Ätiologie der benignen Prostatahyperplasie basiert auf einem gestörten Östrogen-Androgen-Quotienten. Durch eine hohe Konzentration von freien Östradiolen im Plasma wird die Synthese von SHBG in der Leber stimuliert, was zu einer altersabhängigen Abnahme des freien Testosterons und somit zum Anstieg der Relation von freiem Östradiol gegenüber Testosteron von bis zu $40 \%$ führt.

Den Östrogenen wird bzgl. der benignen Prostatahyperplasie eine Reihe von Wirkungen zugesprochen: Stromahyperplasie, Steigerung der Androgenrezeptorpopulation in den Zellkernen der Prostata, Verlängerung der Lebensdauer der Stromazellen, sowie Steigerung der Produktion von SHBG.

Neuerdings wird auch eine Wechselwirkung zwischen Stroma und Epithel in der Pathogenese für die benigne Prostatahyperplasie mit verantwortlich gemacht. Dabei geht man davon aus, daß über verschiedene Wachstumsfaktoren (EGF: epidermaler Wachstumsfaktor; IGF: insulinähnlicher Wachstumsfakor; FGF: Fibroblastenwachstumsfaktor) das Wachstum epithelialer Zellen durch das prostatische Stroma stimuliert wird.

Welchen Stellenwert das als „epitheliales Reawakening“ bezeichnete Phänomen bei der Ätiologie der benignen Prostatahyperplasie einnimmt, ist noch nicht geklärt.

Ein letzter Aspekt ist die Stammzelltheorie. Hierbei wird angenommen, dass endokrine Anomalien oder Umwelteinflüsse das nachfolgende abnorme Wachstumsverhalten der Zelle prägen, sei es eine abnorme Reifung oder Steuerung des Zellerneuerungsprozesses oder eine Verzögerung der normalen Apoptose.

Die folgende Tabelle gibt nochmals einen kurzen Überblick über die derzeit aktuellen Ätiologieansätze der benignen Prostatahyperplasie (51). 
Theorien zur Ätiologie der BPH

DHT-Hypothese erhöhte intrazelluläre DHT-Spiegel

erhöhte 5- $\alpha$-Reduktase-Aktivität

erhöhte Androgenrezeptoren-Spiegel

Gestörter Östrogen- altersbedingt erhöhte Konzentrationen von

Androgenhaushalt

Östradiol und sonstigen Östrogenen.

Abnahme des zirkulierenden, freienTestosterons; erhöhtes SHBG

Stroma-Epithel-

stromale, autokrine Faktoren stimulieren unter

Wechselwirkungen Umständen ein ,epitheliales Reawakening“; zu den verantwotlichen Wachstumsfaktoren gehören u.a. EGF, TGF- $\beta$ und FGF

Stammzelltheorie

abnorme Proliferation von Stammzellen $\rightarrow$ deutliche Überproduktion differenzierter, stromaler und in der Folge epithelialer Zellen

Theorie des ver-

BPH-Gewebe verfügt im Vergleich zu minderten Zelltods gesundem Gewebe über eine geringere Mitosegeschwindigkeit - erhöhte Östrogenspiegel führen zu einer verlängerten Lebensdauer der Prostatazellen

Tabelle 1: Ätiologieansätze der benignen Prostahyperplasie (51) 


\subsection{Symptomatik - Klinisches Bild und Diagnostik}

Die benigne Prostatahyperplasie kann über lange Zeit symptomlos bleiben. Nimmt der hyperplastische Drüsenanteil in der periurethralen Region an Größe zu, so steigt durch die Kompression der prostatischen Harnröhre der Strömungswiderstand an, was bis zur vollständigen Obstruktion und zum Harnverhalt führen kann.

Unterscheiden kann man die Symptome in obstruktive und irritative (9):

Obstruktive Symptome (Entleerungssymptome):

- verzögerter Miktionsbeginn

- abgeschwächter Harnstrahl

- Restharn/unvollständige Entleerung

- Nachträufeln

- intermittierender Harnstrahl

- Überlaufinkontinenz

Irritative Symptome (Füllungssymptome):

- Pollakisurie

- Nykturie

- Urge-Harninkontinenz

- Dysurie

Die zunehmende Symptomatik läßt folgende Einteilungen zu:

1. Nach Alken in drei Stadien (3):

I. Reizstadium (subjektive Symptomatik):

- Pollakisurie

- Nykturie

- Verzögerung des Miktionsbeginns

- Abschwächung des Harnstrahls

II. Restharnstadium (beginnende Dekompensation):

- Restharnbildung

- Harndrang

III. Rückstauungsstadium (Dekompensation der Blasenfunktion):

- Überlaufinkontinenz

- Rückstauungsschäden 
2. Nach Vahlensieck in vier Stadien (64), (65):

I. Mehr oder weniger ausgeprägte benigne Prostatahyperplasie

II. Wechselnde Miktionsstörungen, Uroflow zwischen 10 und $25 \mathrm{ml} / \mathrm{sek}$

III. Permanente Miktionsstörungen, Uroflow kleiner $10 \mathrm{ml} / \mathrm{sek}$, Restharn größer $50 \mathrm{ml}$, Trabekelblase

IV. Restharn größer 100 ml, Dilatationsblase, Stauung der oberen Harnwege

Zur Diagnosestellung führen neben der typischen Anamnese der Internationale Prostata Symptome Score (IPSS), die digital-rektale Untersuchung (DRU), die Uroflowmetrie und ggf. die Urethrozystoskopie, das Ausscheidungsurogramm (AUG) und der transrektale Ultraschall (TRUS). 


\section{Flußdiagramm Diagnostik der benignen Prostatahyperplasie}

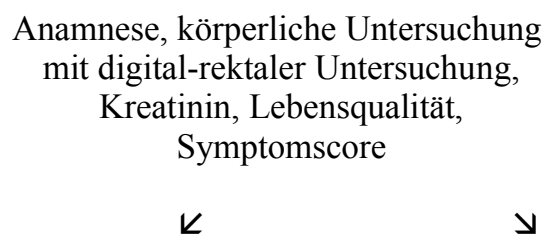

V.a. benigne Prostatahyperplasie

k $\quad y$

ja

nein

- Ende

$\boldsymbol{K}$

$y$

aktive Haltung

$\downarrow$

PSA

K $\quad y$
V.a. andere Erkrankung

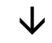

- Zystoskopie

- AUG

- Sonographie

- Abklärung

abwartende Haltung

V.a. Prostatacarcinom

- Abklärung

Uroflow, Restharn

$k \quad y$

V.a. neurologische Erkrankung benigne Prostatahyperplasie

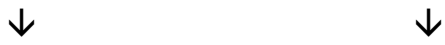

Miktiometrie

$k \quad y$

Neurologische Erkrankung benigne Prostatahyperplasie

$\begin{array}{lll}\text { Therapie } & \text { Therapie } & \text { Therapie }\end{array}$

Tabelle 2: Flussdiagramm Diagnostik der benignen Prostatahyperplasie (7) 


\section{BESCHREIBUNG DER TRANSURETHRALEN RESEKTION DER PROSTATA (TURP)}

Bereits 1932 wurden die ersten Eingriffe an der Prostata mit einem Resektoskop transurethral durchgeführt. Zunehmende Verbesserung der Instrumente und standardisierte Operationstechniken machten die TURP zu dem, was sie heute ist - das Therapieverfahren der ersten Wahl!

Der Eingriff erfolgt in Regionalanästhesie oder Vollnarkose mit einem Resektionsinstrument der Stärke 24 bis 27 Charrière. Unterschiedliche Resektionsschlingen können verwendet werden (Standardschlinge, breite Schlinge). Als Energielieferant wird ein Hochfrequenzgenerator genutzt. Die Resektion kann unter Hochdruck- oder Niederdruckbedingungen in der Blase durchgeführt werden. Niederdruckbedingungen werden entweder durch ein Rückflussresektoskop oder durch Anlage einer suprapubischen Blasenfistel beziehungsweise eines Trokars erreicht. Der Operateur führt diesen Eingriff mit direkter Blickkontrolle durch das Endoskop durch, oder er bedient sich der sogenannten Videoresektion. Hierbei wird über eine Adaptation einer Videokamera an das Instrument das endoskopisch gewonnene Bild am Monitor betrachtet und die Operation am Bildschirm verfolgt. Alle Manipulationen können nach Bedarf aufgezeichnet werden, gleichzeitige Fernsehübertragungen zu einem lernenden Auditorium sind möglich.

Aus der präoperativen Diagnostik (transrektaler Ultraschall) ist das Gesamtvolumen der Prostata sowie das zu entfernende Volumen im Bereich der zentralen und transitionalen Zone bekannt. Somit kann präoperativ nach digital rektalem Tastbefund, transrektalem Ultraschall (TRUS) und auch eventuellem Ausscheidungsurogramm die Indikation zur TURP oder zur offenen Prostatektomie zutreffender als früher gestellt werden.

Die Ausresektion der Prostata bis zur peripheren Zone kann abhängig von der Größe der Prostata in aller Regel in Stundenfrist erledigt werden. Der geübte Operateur kann mindestens 1 Gramm Resektionsgewicht pro Minute entfernen.

Die genaue Kenntnis der Anatomie der Prostata, wie von Mc Neal beschrieben sowie die präund postoperative Darstellung der Prostata im transrektalen Ultraschall haben erkennen lassen, dass auch bei gründlicher Resektion nur etwas mehr als die Hälfte des Prostatavolumens zu entfernen ist. Entscheidend ist, dass eine urodynamisch wirksame und damit auch klinisch relevante Desobstruktion am Blasenauslass und am Apex prostatae gelingt.

Nach Beendigung der Resektion und kontrollierter Blutstillung erfolgt eine Kathetereinlage mit angeschlossener postoperativer Dauerspülung für ein bis zwei Tage (25).

\section{Komplikationen der TURP}

Die wichtigsten intraoperativen Komplikationen sind Blutverlust sowie Spülwassereinschwemmung bis hin zum TUR-Syndrom. Intraoperative klinische und laborchemische Kontrollen sowie der Alkoholeinschwemmtest lassen das TUR-Syndrom rechtzeitig erkennen und Gegenmaßnahmen einleiten (Alkoholeinschwemmtest: durch Zusatz von Alkohol in die Spülwasserflüssigkeit lässt der Alkoholgehalt der Ausatemluft Rückschlüsse über eine Einschwemmung zu). Die arterielle, aber auch venöse Blutung ist in aller Regel endoskopisch $\mathrm{zu}$ beherrschen. Als langfristige postoperative Komplikationen gelten die Entstehung einer narbigen Blasenhalsenge oder eine Harnröhrenstriktur. Eine Harninkontinenz bedingt durch eine operativ erzeugte Läsion des Musculus sphincter externus sollte durch den intraoperativen Sphinktertest zu vermeiden sein. Häufig findet sich eine retrograde Ejakulation (25). 


\section{THERAPIEALTERNATIVEN}

Die letzten Jahre brachten viele neue alternative Therapieansätze mit sich, die im folgenden kurz beschrieben werden.

\subsection{Pharmakologische Ansätze}

\subsubsection{Hormontherapie}

Bereits vor etlichen Jahrzehnten erkannte man durch Kastration und Orchiektomie den Einfluss von Androgenen auf die Prostataproliferation. Aus diesem Gedankenmuster heraus entwickelten sich Therapieansätze mit Antiandrogenen, Östrogenen und anderen endokrin wirksamen Substanzen wie Medrogeston, Spironolacton oder Bromocriptin, zum Teil mit nicht eindeutig nachgewiesener Wirksamkeit.

Neben der chirurgischen Kastration wurde auch eine medikamentöse Therapie mit GnRHAnaloga angewandt, die den Testosteronspiegel binnen zwei bis vier Wochen in den Kastrationsbereich senkten. Obwohl diverse urodynamische Parameter signifikant verbessert wurden, stellten die regelmässig auftretenden Nebenwirkungen wie Hitzewallungen, Schweissausbrüche, Verminderung der Libido und erektile Dysfunktion diese Therapieform weit in den Hintergrund.

Antiandrogene und gestagene Wirkung besitzt das Hydroxyprogesteronderivat Cyproteronacetat. Die antiandrogene Wirkung beruht auf einer kompetitiven Hemmung der Androgenrezeptoren, der gestagene Effekt führt gleichzeitig zu einer Hemmung der Gonadotropinsekretion im Hypophysenvorderlappen.

Keine gestagene Aktivität zeigt das nichtsteroidale Antiandrogen Flutamid, welches nach seiner Metabolisierung zum aktiv wirksamen Hydroxyflutamid die Bindung von Testosteron und/oder DHT am Androgenrezeptor kompetitiv hemmt. 


\begin{tabular}{|c|c|c|}
\hline Medikamente & Wirkungsweise & Nebenwirkungen \\
\hline $\begin{array}{l}\text { Echte } \\
\text { Antiandrogene }\end{array}$ & \multirow{3}{*}{$\begin{array}{l}\text { Kompetitive } \\
\text { Androgenrezeptor- } \\
\text { blockade, Hemmung } \\
\text { der } 5 \alpha \text {-Reduktase }\end{array}$} & \multirow[b]{2}{*}{$\begin{array}{l}\text { Brustschmerzen, } \\
\text { Gynäkomastie, } \\
\text { in ca. } 2-3 \% \text { sexuelle } \\
\text { Dysfunktionen }\end{array}$} \\
\hline $\begin{array}{l}\text { - Flutamid } \\
\text { - Finasterid }\end{array}$ & & \\
\hline $\begin{array}{l}\text { Androgenablativ } \\
\text { wirkende } \\
\text { Medikamente }\end{array}$ & & \\
\hline - GnRH-Analoga & $\begin{array}{l}\text { Hemmung der } \\
\text { Sekretion von LH im } \\
\text { Hypophysen- } \\
\text { vorderlappen }\end{array}$ & $\begin{array}{l}\text { Hitzewallungen, } \\
\text { Gynäkomastie, } \\
\text { Libidoverlust, } \\
\text { Impotenz }\end{array}$ \\
\hline $\begin{array}{l}\text { Antiandrogen und } \\
\text { androgenablativ } \\
\text { wirkende } \\
\text { Medikamente }\end{array}$ & & \\
\hline - Cyproteronacetat & $\begin{array}{l}\text { Kompetitive } \\
\text { Androgenrezeptor- } \\
\text { blockade, Hemmung } \\
\text { der Sekretion von LH } \\
\text { im HVL }\end{array}$ & $\begin{array}{l}\text { Impotenz, } \\
\text { Libidoverlust }\end{array}$ \\
\hline
\end{tabular}

Tab. 3: Übersicht über antiandrogene und androgenablative Substanzen

Eine Sonderstellung nimmt der 5 $\alpha$-Reduktase-Hemmer Finasterid ein:

Finasterid ist einer der wenigen in Deutschland klinisch zugelassenen $5 \alpha$-Reduktase-Hemmer. Das synthetische 4-Azasteroid ähnelt strukturell sowohl dem Testosteron als auch dem DHT und hemmt selektiv das Isoenzym 2 der $5 \alpha$-Reduktase, welches die prädominante intraprostatische Form darstellt.

Das Isoenzym 1 der 5 $\alpha$-Reduktase kommt hauptsächlich in der Leber und der Haut vor und wird durch Finasterid in seiner Wirkung kaum gehemmt. Dadurch wird bei erhaltenem Serumtestosteron selektiv der intraprostatische DHT-Spiegel gesenkt, da eine Umwandlung von Testosteron zu DHT nicht mehr möglich ist. Die Wirkung der 5 $\alpha$-Reduktase-Hemmer besteht somit in einer Volumenreduktion der peripheren und periurethralen Drüsen der Prostata, also der statischen Komponente der benignen Prostatahyperplasie (30), (48).

Ein sinnvoller Einsatz ist jedoch nur bei Prostatae kleiner und mittlerer Volumina möglich. (63). 


\subsection{2. $\alpha 1$-Adrenorezeptorantagonisten ( $\alpha$-Blocker)}

Grundlage für die Behandlung mit $\alpha$-Blockern ist die hohe Dichte an $\alpha 1$-Rezeptoren in der menschlichen Prostata. Als erste Substanz wurde Anfang der 70er Jahre der nicht selektive $\alpha$-Adrenorezeptorantagonist Phenoxybenzamin eingesetzt, der bei

$30 \%$ der Patienten jedoch Nebenwirkungen wie Hypotonie, Reflextachykardie, Müdigkeit, Schwindel, „verstopfte Nase“ und retrograde Ejakulation hervorrief. Durch Einführung selektiver $\alpha 1$-Blocker konnten die Nebenwirkungen zwar verringert werden, dennoch hatten viele Patienten mit Schwindel, Kopfschmerzen, trockenem Mund, orthostatischer Dysregulation, Tachykardie, Akkomodationsstörungen sowie Sexualstörungen zu kämpfen.

Bei weiterer Forschung konnte man drei Subtypen von $\alpha 1$-Rezeptoren identifizieren, von denen der $\alpha 1$ A-Adrenorezeptor vorwiegend in der menschlichen Prostata exprimiert wird, welcher vor allem für die Tonuserhöhung der glatten Muskelzellen der Prostata verantwortlich ist. Diese Muskelzellen machen immerhin 20-40 \% des Stromas der Prostata aus und entsprechen der dynamischen Komponente der Obstruktion; die statische oder mechanische Komponente entspricht der Vergrößerung des Organs (hyperplastisches Gewebe an sich) (27), (2).

\begin{tabular}{|c|c|c|}
\hline nicht selektiv & & Phenoxybenzamin \\
\hline \multirow[t]{2}{*}{$\alpha 1$-selektiv } & kurze HWZ & Prazosin, Alfuzosin $(<5 \mathrm{~h})$ \\
\hline & lange HWZ & $\begin{array}{l}\text { Doxazosin }(9-12 \mathrm{~h}) \\
\text { Terazosin }(12 \mathrm{~h})\end{array}$ \\
\hline $\begin{array}{l}\alpha 1 \mathrm{~A} \text {-selektiv } \\
\text { (uroselektiv) }\end{array}$ & & Tamsulosin \\
\hline
\end{tabular}

Tab. 4: Beispiele von $\alpha$-Blockern unterschiedlicher Selektivität 


\subsubsection{Phytotherapie}

Mit einem Marktanteil von zur Zeit etwa $90 \%$ bei der medikamentösen Behandlung der benignen Prostatahyperplasie wird das Ausmass der Akzeptanz der Phytopharmaka in der Bevölkerung deutlich. Ursächlich dafür sind wohl die Bevorzugung pflanzlicher, „ungefährlicher“" Arzneimittel, das seltene Auftreten von Nebenwirkungen sowie die niedrigen Tagesdosiskosten.

Neuere klinische Studien sollen zwar die Wirkung der Phytopharmaka belegen - dennoch ist auch das Internationale Konsensualkomitee der WHO der Ansicht, dass es sich bei den Phytopharmaka möglicherweise um Placebos handelt (13).

Folgende Übersicht stellt die derzeit gängigsten Mittel kurz vor:

\begin{tabular}{|c|c|c|}
\hline Name des Mittels & postulierte Wirkung & Nebenwirkungen \\
\hline $\begin{array}{l}\text { Sägepalmenfrucht } \\
\text { (Sabal serrulata) }\end{array}$ & $\begin{array}{l}\text { Hemmung der } \\
5 \alpha \text {-Reduktase und } \\
\text { antiexsudativer Effekt }\end{array}$ & Magenbeschwerden \\
\hline $\begin{array}{l}\text { Brennesselwurzel } \\
\text { (Urtica dioica und urens) }\end{array}$ & $\begin{array}{l}\text { Reduktion der Bin- } \\
\text { dungskapazität von } \\
\text { sexualhormonbinden-dem } \\
\text { Globulin (SHBG) und } \\
\text { Hemmung der Aromatase }\end{array}$ & $\begin{array}{l}\text { Magen-Darm- } \\
\text { Beschwerden }\end{array}$ \\
\hline $\begin{array}{l}\text { Kürbissamen } \\
\text { (Cucurbita pepo und } \\
\text { Cultivars davon) }\end{array}$ & $\begin{array}{l}\text { Senkung der intraprostatischen } \\
\text { DHT-Konzentration }\end{array}$ & \\
\hline $\begin{array}{l}\text { Roggenpollenextrakt } \\
\text { (Serale cereale, Phleum } \\
\text { pratense und } \\
\text { Zea mays) }\end{array}$ & $\begin{array}{l}\text { Hemmung der } \\
\text { Cyclooxygenase und } \\
\text { Lipoxygenase; } \\
\text { spasmolytischer Effekt; } \\
\text { Hemmung der } \\
\text { 5 } \alpha \text {-Reduktase }\end{array}$ & $\begin{array}{l}\text { Überempfindlichkeits- } \\
\text { reaktionen }\end{array}$ \\
\hline $\begin{array}{l}\beta \text {-Sitosterol } \\
\text { (Hypoxis rooperi) }\end{array}$ & bisher noch unbekannt & \\
\hline
\end{tabular}

Tab. 5: Beispiele von Phytotherapeutika bei der Behandlung der benignen Prostatahyperplasie (13), (53) 


\subsection{Instrumentelle Therapie}

\subsubsection{Wärmetherapie}

Die Ergebnisse bei der Behandlung der benignen Prostatahyperplasie mit Wärme sind im wesentlichen von der Quantität der thermischen Energie abhängig. Während Temperaturen unter $45^{\circ} \mathrm{C}$ keinen Einfluß auf das Prostatagewebe zeigen, können durch höhere Temperaturbereiche Gewebsnekrosen erreicht werden. Diese $45^{\circ} \mathrm{C}$-Schwelle grenzt somit folgende Verfahren voneinander ab:

\subsubsection{Hyperthermie}

Transurethral oder transrektal eingebrachte Geräte erwärmen durch hochfrequenten Strom des Mikrowellenbereichs das Prostatagewebe auf Temperaturen zwischen $42^{\circ} \mathrm{C}$ und $45^{\circ} \mathrm{C}$. Da die Besserung der Symptome in der Regel deutlicher ist als die objektiven Parameter, nimmt man an, daß die Effekte vorwiegend über Schädigungen von $\alpha$-Rezeptoren und Nerven vermittelt werden. Desweiteren muß von einem hohen Placeboeffekt ausgegangen werden.

\subsubsection{Thermotherapie - Transurethrale Mikrowellentherapie - TUMT}

Im Gegensatz zur Hyperthermie sind bei der Thermotherapie mit Temperaturen über $45^{\circ} \mathrm{C}$ Gewebsnekrosen (Koagulationsnekrosen) nachweisbar. Bei diesem - auch als TUMT (transurethrale Mikrowellenthermotherapie) bezeichneten Verfahren - werden intraprostatische Temperaturen zwischen $45^{\circ} \mathrm{C}$ und $60^{\circ} \mathrm{C}$ erreicht, wobei die Urethra selbst durch ein Kühlsystem geschont wird.

Man unterscheidet zwischen der Niedrigenergie-(NE-)TUMT mit intraprostatischen Temperaturen bis $55^{\circ} \mathrm{C}$ und der Hochenergie-

(HE-)TUMT mit Temperaturen $>55^{\circ} \mathrm{C}$. Die HE-TUMT erreicht eine Desobstruktion, wobei bei der NE-TUMT vornehmlich die Symptomatik des Patienten gebessert wird, ohne die objektiven Parameter zu verbessern. Vorteil für dieses Verfahren ist die narkosefreie Behandlung und die Möglichkeit einer ambulanten Therapie. Wie auch bei manch anderen Verfahren ist hier eine passagere Harnableitung mittels beispielsweise eines suprapubischen Blasenkatheters notwendig. Langzeitdaten sind nur begrenzt verfügbar (23), (29), (31) (51).

\subsubsection{Transurethrale Nadelablation - TUNA}

Die Transurethrale Nadelablation (TUNA) ist eine neuartige Technik, bei der Strahlenfrequenzenergie eingesetzt wird, die an die Seitenlappen der Prostata über zwei an der Spitze einer Sonde befestigte Nadeln abgegeben wird. Die Temperatur in der Prostata kann auf Werte von $100^{\circ} \mathrm{C}$ erhöht und mittels Aufzeichnung der Rektumtemperatur bestimmt werden. Jeder Seitenlappen wird 2-4 mal behandelt. Die Ergebnisse von Langzeitstudien zu TUNA im Vergleich zu TURP müssen noch abgewartet werden (51), (25). 


\subsubsection{Focusierter Hochfrequenzultraschall - HIFU}

Bei diesem Verfahren wird Ultraschallenergie spezifisch auf das hyperplastische Prostatagewebe focusiert, die so eine intensive lokale Erhitzung mit Zerstörung des entsprechenden Gewebes verursacht. Auch dieser Therapieansatz steht noch in der Erprobung; zur Zeit wird ein kombinierter bildgebender transrektaler Transducer für die Therapie am Menschen entwickelt (51).

\subsubsection{Kryotherapie}

Bereits 1966 wurden die ersten kryochirurgischen Verfahren bei der Behandlung der benignen Prostatahyperplasie eingesetzt. In Lokalanästhesie werden die Kältesonden inzwischen transperineal in die Prostata unter Ultraschallkontrolle eingebracht und auf Werte zwischen $-240^{\circ} \mathrm{C}$ und $-260^{\circ} \mathrm{C}$ gekühlt. Dabei entstehen eine Reihe von Eisbällen in der Prostata, die nach einer Gefrierzeit von 4-16 Minuten das Prostatagewebe verschorfen lassen. Nach Ausscheidung des Prostataschorfs über einen Harnröhrenkatheter entsteht ähnlich wie nach der TURP eine relativ große Höhle. Aufgrund der schlechten Abschätzbarkeit der Beschädigung des angrenzenden Gewebes und seinen Komplikationen wie erektiler Dysfunktion, prostatorektalen Fisteln oder Ureterverletzungen befindet sich dieses Verfahren nach wie vor im Versuchsstadium (51).

\subsubsection{Mechanische Therapieansätze}

\subsubsection{Ballondilatation}

Ein eher historisches Verfahren stellt die Dilatation der prostatischen Harnröhre und des Blasenhalses mit einem Ballonkatheter dar, der über 10 Minuten mit einem Druck von 3 Atmosphären auf ca. 25-35 mm aufgeblasen wird. Da die hierdurch erreichten Effekte (vor allem Sprengung der vorderen Prostatakommissur) langfristig nicht anhalten, ,scheint die Ballondilatation der Prostata eher für die historische Mülltonne der nicht hilfreichen medizinischen Geräte bestimmt zu sein“ (Valae et al., 1993).

\subsubsection{Intraprostatische Implantate}

Erstmals wurde 1980 die intraprostatische Spirale, eine Art zirkuläre Feder aus rostfreiem Edelstahl verwendet, die das prostatische Harnröhrenlumen offenhalten soll. Inkrustationen mit Urin-Präzipitaten sowie das Verrutschen der Spirale in Richtung Blase zwangen aber zur Weiterentwicklung. In der Folgezeit wurden aufspannbare Prostata-Stents aus Titan verwendet, welche korrosionsbeständig seien und vollständig epithelialisiert würden, was dem Problem der Inkrustation vorbeugen sollte. Eine irritative Symptomatik durch den Fremdkörper ist häufig zu erwarten. Ein großer prostatischer Mittellappen verbietet die Einlage eines intraprostatischen Stents.

Generell muß jedoch erwähnt werden, daß die Metallspiralen und Stents keine Alternative zur operativen Therapie der benignen Prostatahyperplasie darstellen, allenfalls zur Langzeitkatheterisierung

(25), (31), (51), (55). 


\subsubsection{Lasertherapie}

Obwohl bereits 1979 die ersten experimentellen Untersuchungen und klinischen Anwendungen des Lasers an der Prostata publiziert wurden, rückte die Laserbehandlung der benignen Prostatahyperplasie erst mit Beginn der 90er Jahre zunehmend in den Blickpunkt des Interesses. Im folgenden werden kurz die verschiedenen Systeme und Techniken vorgestellt:

\subsubsection{Transurethrale Laserkoagulation der Prostata}

Unter diesem Terminus werden alle Techniken bzw. Verfahren zusammengefasst, bei denen das periurethrale benigne Prostatahyperplasie-Gewebe (und in der Regel die Urethra) mit Hilfe eines in der prostatischen Harnröhre befindlichen Laserapplikators bestrahlt und somit koaguliert bzw. vaporisiert wird. Verwendung findet dabei der Nd: YAG-Laser mit einer Wellenlänge von $1064 \mathrm{~nm}$, der eine hohe Eindringtiefe und Streuung der Laserstrahlung gewährleistet (24).

Eine vornehmlich vaporisierende Wirkung wird mit dem KTP-Laser oder HO: YAG-Laser erreicht.

Bei der transurethralen Laserkoagulation bzw. -vaporisation haben sich im Laufe der Zeit zwei verschiedene Methoden herauskristallisiert: TULIP und VLAP.

Die TULIP - transurethrale ultraschallgesteuerte laserinduzierte Prostatektomie - bedient sich, wie der Name schon verrät, der Hilfe der Sonographie. Dabei wird die Strahlführung des Lasers (Kontaktlaser) durch zwei für den transurethralen Einsatz konzipierten 7,5 MHz-Sektor Ultraschalltransducern kontrolliert, welche ein Echtzeitbild eines $90^{\circ}$-Sektors der Prostata bis in eine Tiefe von $5 \mathrm{~cm}$ erzeugen.

Im Gegensatz dazu erfolgt die Laserkoagulation bei der VLAP - visuelle laserassistierte Prostatektomie - unter direkter Sicht. Die Bestrahlung der Prostata erfolgt dabei sichtkontrolliert über herkömmliche Urethrozystoskope oder speziell konstruierte Laserzystoskope. Bei dieser Technik kann kein Gewebe zur Histologie gewonnen werden. Endoskopisch geringgradige Obstruktionen sind damit gut zu beseitigen, die Blutung ist geringfügig. Eine grossvolumige Prostata ist damit nicht sinnvoll $\mathrm{zu}$ behandeln. Wegen der teuren Technologie (begrenzt einsetzbare Laserfaser, eigener Lasergenerator) und der limitierten Effizienz ist die Technik in ihrem Einsatz begrenzt.

Beim „non-contact laser“ werden speziell konstruierte Lasersonden genutzt, die Licht an der Spitze der Fasern ablenken (Sidefire-Technik) und berührungsfrei auf das Gewebe bündeln. Auch mit dieser Technik läßt sich Gewebe verdampfen, eine Histologiegewinnung ist nicht möglich. Es besteht in Einzelfällen die Möglichkeit, die Sidefire-Technik ambulant in Lokalanästhesie mit dem Zystoskop durchzuführen.

\subsubsection{Interstitielle Laserkoagulation der Prostata - ILK}

Im Gegensatz zu den bisher genannten Verfahren erfolgt bei der ILK die Bestrahlung der benignen Prostatahyperplasie nicht von der Oberfläche, sondern von innen, da hierbei das Applikationssystem in das Gewebe eingestochen wird. Das Prinzip der Methode besteht darin, innerhalb der Prostata Nekrosezonen entstehen zu lassen, die die Seiten- und Mittellappen der Prostata schrumpfen lassen sollen, um den Blasenhals zu öffnen und somit die Obstruktion zu 
beseitigen. Das gewünschte Ergebnis ist unmittelbar postoperativ nicht zu erkennen. Häufig kommt es nach Laserapplikation zu einem Harnverhalt, so dass bei der primären Sitzung bereits eine suprapubische Fistel eingelegt werden sollte, die teilweise über Wochen belassen werden muss. Das Einbringen der Lichtleiter kann alternativ transurethral, perineal transkutan oder kombiniert durchgeführt werden.

Die Vorteile gegenüber der transurethralen Koagulation liegen zum einen darin, daß die Nekrose keinen Anschluß an das Lumen der Urethra hat, die zudem nicht zerstört wird; desweiteren besteht hier auch die Möglichkeit, durch mehrere Applikationen nahezu beliebig große Volumina zu koagulieren.

Kritisch jedoch ist die Überhitzung, die zur Karbonisation des Gewebes führt. Die Bestrahlung darf daher nur mit ralativ geringen Leistungen erfolgen, was den Nachteil langer Applikationszeiten mit sich bringt (19), (25), (31), (34), (45), (51), (55).

\subsubsection{Sonstige invasive Verfahren}

\subsubsection{Transurethrale Inzision der Prostata - TUIP}

Die auf Arbeiten von Orandi zurückgehende Technik ist besonders für die Behebung einer konstriktiven Obstruktion bei wenig ausgeprägten Mittel- und Seitenlappen geeignet. Die Technik kann auch bei der Blasenhalsstenose angewandt werden.

Hinter diesem Verfahren verbirgt sich eine Elektroinzision des Blasenhalses, die bis in die Höhe des Colliculus seminalis durchgezogen wird. Die Inzision kann beidseits oder einseitig durchgeführt werden, in aller Regel in der Position 5 und 7 Uhr. Sie ist indiziert bei kleiner $(<30$ Gramm), fibrotisch umgewandelter Prostata, die nicht durch ihr Volumen, sondern durch die Konstrikton der Urethra zur Obstruktion führt.

Als Vorzüge der TUIP werden signifikant kürzere OP-Zeiten, geringere Komplikationsraten, geringere Blutverluste, kürzere Katheterliegezeiten und letztendlich kürzerer stationärer Krankenhausaufenthalt angegeben. Andererseits scheint für die TUIP im Laufe der Zeit nach dem Eingriff eine Verschlechterung der Symptome einzutreten, da eine effektive Beseitigung des obstruierenden hyperplastischen Gewebes nicht erfolgt (25), (31), (51), (55).

\subsubsection{Transurethrale Vaporisation der Prostata - TUVP}

Die TUVP stellt eine Modifikation der konventionellen TURP dar.

Im Gegensatz zur Koagulation wird durch hohe Frequenzen konventioneller Diathermie eine Verdampfung des Gewebes erreicht. Eine eigens entwickelte, profilierte Roller- oder Kugelelektrode (sog. Vaportrode) wird dabei langsam über die Oberfläche des obstruierenden Prostatagewebes geführt, wobei das Epithel und das darunter liegende Gewebe bis auf eine Tiefe von einigen Millimetern zerstört wird. Ebenso wie bei der TURP wird hiermit ein Lumen erzielt. Vorteile dieser Methode sind eine kurze Behandlungszeit sowie ein nur minimaler Blutverlust. Andererseits ist eine relativ lange Katheterisierung nötig, desweiteren besteht die Gefahr einer sekundären Blutung etwa eine Woche nach der Behandlung (25), (51), (55). 


\subsubsection{Offene Prostatektomie}

Die offene Prostatektomie hat nach wie vor ihre Berechtigung bei grossen Prostaten mit einem Gewicht von ca. 100 Gramm und mehr. Weitere Indikationen sind grosse Blasensteine, langstreckige posteriore Harnröhrenengen sowie Patienten mit schweren Coxarthrosen und Wirbelsäulenankylosen, die ungeeignet für die Steinschnittlage (als Voraussetzung für die TURP) sind.

Bei den offenen Verfahren haben sich zwei verschiedene Zugangswege durchgesetzt, deren Vorteile in folgender Gegenüberstellung dargestellt werden:

\begin{tabular}{|l|l|}
\hline $\begin{array}{l}\text { Suprapubischer } \\
\text { (transvesikaler) } \\
\text { Zugang }\end{array}$ & Retropubischer Zugang \\
& \\
- gleichzeitige Entfernung von & - direkter Zugang zur Prostata \\
Blasensteinen möglich & (da Blase nicht eröffnet wird) \\
- gleichzeitige Entfernung von & - geringeres Risiko von \\
Blasendivertikeln möglich & Harnfisteln \\
& - kein suprapubischer Blasen- \\
& katheter nötig \\
& - geringerer Blutverlust \\
& (Blutstillung unter Sicht \\
& möglich) \\
& \\
\hline
\end{tabular}

Tab. 6: Vorteile der verschiedenen Zugangswege (offene Operation) (4), (20), (31), (51)

\subsubsection{Ablativ operative Verfahren in klinischer Erprobung}

\subsubsection{Transurethrale Rotoresektion der Prostata}

Um die Nachteile der Blutungsrate bei der Standardschlingen- resektion der Prostata und der reduzierten Gewebeablation der Elektrovaporisation der Prostata auszuschalten, wurde durch die Urologische Universitätsklinik Mannheim eine Optimierung durch die neu entwickelte transurethrale Rotoresektion versucht (25). Hierbei ermöglicht eine aktiv durch einen Mikromotor angetriebene, rotierende Gewebefrässkopfelektrode eine Gewebekoagulation, -vaporisation und eine zusätzliche mechanische Gewebeablation.

Dieses Verfahren befindet sich in der klinischen Erprobung.

\subsubsection{Koagulierndes intermittierendes Schneiden - KIS cocut BMP}

Als grosser Vorteil bei der operativen Therapie der benignen Prostatahyperplasie steht der sofortige Therapieerfolg bei besten Langzeitergebnissen. Der entscheidende Nachteil der TURP ist jedoch die methodenbedingte perioperative Morbidität (25). Insbesondere der durch die Operation bedingte Blutverlust und die sogenannte Spülflüssigkeitseinschwemmung bis hin zum TUR-Syndrom führten in den letzten Jahren zum vermehrten Einsatz alternativer Behandlungsformen. Ein anderer Weg wurde an der Urologischen Klinik und Poliklinik der Technischen Universität, Klinikum rechts der Isar, München, beschritten: 
Nicht der Einsatz alternativer Technologien, sondern die Verbesserung der TURP wurde als Ziel gesetzt. In Zusammenarbeit mit dem Institut für Hoch- und Höchstfrequenztechnik der Universität der Bundeswehr wurde seit Ende 1994 eine Hochfrequenztechnik entwickelt, die die perioperative Morbidität der TURP minimiert (25). Hierzu wurde ein handelüblicher Generator in seiner Funktion erweitert. Daraus resultierte das „koagulierende Schneiden“ mit Koagulationsund Schneideperioden. Es zeigte sich eine geringere intraoperative Blutung, jedoch verursachte die Methode eine Reduzierung der Schneidegeschwindigkeit. Deshalb kam es zu Entwicklung des „koagulierenden intermittierenden Schneidens“ mit Pulsen hoher Spannung (KIS). Hierbei zeigten sich klinisch vergleichbare Ergebnisse zum „koagulierenden Schneiden“. Ungünstig stellte sich jedoch die Entwicklung von Gasblasen in der Spülflüssigkeit dar. In einer dritten Phase wird das „,koagulierende intermittierende Schneiden“ mit Pulsen konstanter Spannung und Regelung der Pulspausen (KIS cocut BMP) erprobt. Klinische Erfahrungen zeigen, dass diese Technik einen blutarmen Gewebeschnitt erlaubt. Der semiquantitative Nachweis im Ex-vivoModell zeigt eine statistische Relevanz, ohne im Vergleich zur Standardresektion langsamer zu sein. Diese verbesserte Technologie senkt die perioperative Morbidität der TURP und behält die Effizienz der Methode bei. Die Beibehaltung aller klassischen Vorgehensweisen, wie auch des gewohnten Resektionsinstrumentariums ist möglich (10). 


\section{ZIELE DER STUDIE}

Die retrospektive Analyse der transurethralen Resektion der Prostata anhand des Patientengutes der urologischen Klinik und Poliklinik, Klinikum rechts der Isar umfasst folgende Ziele:

1. Quantitative Erfassung der Spätkomplikationen nach TURP bei benigner Prostatahyperplasie

2. Überprüfung des Stellenwertes der TURP gegenüber der Vielzahl neuer Therapieansätze 


\section{MATERIAL UND METHODIK}

$\mathrm{Zu}$ Beginn der Studie wurden aus dem Operationsbuch, in dem alle durchgeführten Operationen chronologisch aufgeführt sind, die in Frage kommenden Patienten selektiert. Berücksichtigt wurden alle Patienten mit benigner Prostatahyperplasie, die einer TURP unterzogen wurden. Der Erhebungszeitraum lag zwischen Januar 1989 und Dezember 1997.

Auf eine Auswahl bezüglich der Operateure wurde mit Absicht verzichtet, um dem Anspruch der Vollständigkeit hinsichtlich der „Fehlerquellen“ bei der TURP gerecht zu werden.

Von den in Betracht kommenden Patienten wurden Name, Vorname, Geburts- und Operationsdatum notiert. Anhand dieser Daten war eine eindeutige Zuordnung zu den Krankenakten möglich.

Es wurden die Daten von über 1000 Patienten erhoben.

Grundlage der weiteren Datenerhebung waren nun die Anamnesebögen, Verlaufskurven, Anästhesieaufzeichnungen, OP-Berichte, Konsile, Ambulanzakten, radiologische und laborchemische Unterlagen, diverse externe Voruntersuchungen, die von den jeweiligen Urologen schriftlich festgehalten wurden, sowie die Entlassungsbriefe.

Die ermittelten Daten wurden in eine Computerdatenbank eingegeben, welche in die fünf Themenbereiche Hauptmenü, Diagnostik, Therapie, Komplikationen und Nachsorge unterteilt war .

Der Diagnostikteil erfaßte allgemeine und urologische Vor- und Begleiterkrankungen, Voruntersuchungen, Symptome sowie die Diagnose und die OP-Indikation.

Die Art des Eingriffs sowie die wichtigsten prä- und intraoperativen Labordaten wurden im Kapitel Therapie erfaßt. Hier wurden auch evtl. benötigte Bluttransfusionen festgehalten.

Der Komplex der Komplikationen wurde in drei Sparten unterteilt, nämlich in intraoperative (wobei hier urologisch und allgemeine Komplikationen getrennt behandelt wurden) und in Frühund Spätkomplikationen.

Ergebnisse der ambulanten Nachuntersuchungen, sowie die Auswertung des zugesandten Fragebogens (siehe Anhang) wurden in der Rubrik Nachsorge eingearbeitet.

Der den Patienten zugesandte Fragebogen gab Aufschluss über den derzeitigen Gesundheitszustand sowie über die Zufriedenheit des Patienten. Speziell gefragt waren Veränderungen (vor/nach der Operation) der subjektiven Beschwerden des Harnstrahls, der Miktionshäufigkeit, der Gliedsteife, der Ejakulationsfähigkeit sowie der Harnkontinenz; daneben sollten die Patienten auch ihre Lebensqualität vor und nach der Operation klassifizieren.

Nach dreimonatiger Rücklaufzeit wurden die Daten der Fragebögen in die jeweiligen Kapitel der Computermaske eingegeben, wobei die Fragebögen den entsprechenden Datensätzen durch Patientenname und Geburtsdatum einwandfrei zugeordnet werden konnten.

Somit konnten die kompletten Datensätze ausgewertet werden. 


\section{ERGEBNISSE}

Als Grundlage zur Bewertung erfolgt zuerst eine Beschreibung der präoperativen Ausgangssituation, anschliessend der perioperativen Problematik sowie des postoperativen Verlaufes.

Die Angaben der Prozentzahlen beziehen sich immer auf eine Gesamtpatientenzahl von 1011 Fällen (bzw. in Klammern angegebene auswertbare Patientendateien).

\subsection{Präoperative Situation}

Um eine genaue Beurteilung der Ergebnisse der transurethralen Resektion der Prostata geben zu können, ist eine exakte Analyse des Patientengutes bzgl. allgemeinen sowie speziell urologischen Vorerkrankungen zur Skizzierung der präoperativen Ausgangssituation notwendig.

\subsubsection{Vor- und Begleiterkrankungen}

Zunächst wurde auf die allgemein-internistischen Nebendiagnosen der Patienten eingegangen. Hierbei zeigten sich bei 113 Patienten $(11,2 \%)$ eine therapiebedürftige koronare Herzkrankheit (KHK), 47 mit Herzinsuffizienz (4,7\%), Coronarbypass 16 (1,6\%), Coronarstent 2 (0,2\%).

Bei 89 Patienten $(8,8 \%)$ bestanden Rhythmusstörungen, 105 standen unter Antikoagulation $(10,4 \%)$, Z.n. tiefer Beinvenenthrombose $6(0,6 \%)$, Z.n. Lungenembolie $5(0,5 \%)$, einen Diabetes mellitus (Typ I und II) wiesen 38 Patienten auf $(3,8 \%)$.

\begin{tabular}{l|ll} 
Erkrankung & Anzahl & in Prozent (von1011) \\
KHK & 113 & 11,2 \\
Herzinsuffizienz & 47 & 4,7 \\
ACVB & 16 & 1,6 \\
Coronarstent & 2 & 0,2 \\
Rhythmusstörungen & 89 & 8,8 \\
Z.n. Thrombose & 6 & 0,6 \\
Z.n. Lungenembolie & 5 & 0,5 \\
Antikoagulation & 105 & 10,4 \\
Diabetes mellitus & 38 & 3,8
\end{tabular}

Tabelle 7: Vor- und Begleiterkrankungen 


\subsubsection{Urologische Vorerkrankungen}

Als urologische Vorerkrankung lag bei 34 Patienten $(3,4 \%)$ eine Harnröhrenstriktur, bei 26 Patienten $(2,6 \%)$ eine Prostatits, bei 28 Patienten (2,8\%) ein Blasentumor, bei 23 Patienten $(2,3 \%)$ eine Epididymitis und bei 63 Patienten (6,2\%) Blasensteine vor.

\begin{tabular}{l|ll} 
Erkrankung & Anzahl & in Prozent (von 1011) \\
HR-Striktur & 34 & 3,4 \\
Prostatitis & 26 & 2,6 \\
Blasentumor & 28 & 2,8 \\
Epididymitis & 23 & 2,3 \\
Blasensteine & 63 & 6,2
\end{tabular}

Tabelle 8: Urologische Vorerkrankungen

\subsubsection{Vorgeschaltete konservative Therapie}

Von insgesamt 991 befragten Patienten hatten sich 135 (13,6\%) einer konservativen Therapie mit $\alpha$-Blockern, $\alpha$-Reduktase-Hemmern oder Phytotherapeutika unterzogen, 856 Patienten $(86,4 \%)$ stellten sich ohne derartige Vorbehandlung zur Operation vor.

\subsubsection{Urologische Voroperationen/Eingriffe}

Eine Einflussnahme auf das Outcome dürften neben Voroperationen im Bereich der Prostata auch weitere transurethrale Therapieverfahren und Methoden der Harnableitung nehmen, 59 Patienten hatten bereits eine transurethrale Prostataresektion (5,8\%) hinter sich. An Eingriffen wurden des weiteren angegeben die transurethrale Resektion der Blase (TURB), Lithotrypsie und Prostatastent mit je 1 Patienten $(0,1 \%)$ sowie die Urethrotomia interna nach Sachse oder Otis mit 8 Patienten $(0,8 \%)$.

Transurethrale Katheterisierungen hatten bereits 23 Patienten hinter sich (2,3\%).

Bei der stationären Aufnahme waren 151 Patienten (14,9\%) mit einer suprapubischen Harnableitung, 120 Patienten (11,9\%) mit einem Dauerkatheter versorgt.

$\begin{array}{llllll}\text { Eingriff } & \begin{array}{l}\text { Klinikum } \\ \text { rechts } \\ \text { Isar }\end{array} & \text { auswärts } & \text { gesamt } & \begin{array}{l}\text { in Prozent } \\ \text { (von1011) }\end{array} \\ \text { TURP } & 25 & 34 & 59 & 5,8 \\ \text { TURB } & 1 & 0 & 1 & 0,1 \\ \text { Lithotrypsie } & 1 & 0 & 1 & 0,1 \\ \text { Prostatastent } & 0 & 1 & 1 & 0,1 \\ \text { Urethrotomie } & 0 & 8 & 8 & 0,8 \\ \text { Einmalkatheter } & 2 & 21 & 23 & 2,3 \\ \begin{array}{l}\text { Dauerkatheter } \\ \text { suprapubischer }\end{array} & 12 & 108 & 120 & 11,9 \\ \text { Katheter } & 35 & 116 & 151 & 14,9 \\ \text { Tabelle } & & & & \end{array}$

Tabelle 9: Urologische Voroperationen/Eingriffe 


\subsubsection{Symptomatik}

Das subjektive Beschwerdebild der Patienten vor der Operation war über die Anamnese durch den Arzt bei stationärer Aufnahme festgehalten worden.

Über obstruktive Probleme berichteten 962 Patienten (95,1\%), 25 Patienten über irritative (2,5\%), keine Angaben machten 24 Patienten (2,4\%).

Die Gesamtheit der 1011 Patienten klagte in absteigender Häufigkeit über Nykturie (78,7\%), Harnstrahlabschwächung (58,6\%), Harnverhalt (26,6\%), Dysurie $(22,1 \%)$, Restharngefühl (18,8\%), Startverzögerung (17,3\%), Nachtröpfeln (16,5\%), Makrohämaturie (7,5\%), Urgesymptomatik (7,3\%), Überlaufinkontinenz (4,2\%), rezidivierenden Harnwegsinfekten (3,9\%), Urgeinkontinenz (3,3\%) sowie Stressinkontinenz $(0,8 \%)$.

\begin{tabular}{|c|c|c|}
\hline Symptom & Anzahl & $\begin{array}{l}\text { in Prozent } \\
\text { (von 1011) }\end{array}$ \\
\hline Nykturie & 796 & 78,7 \\
\hline Harnstrahlabschwächung & 592 & 58,6 \\
\hline Harnverhalt & 269 & 26,6 \\
\hline Dysurie & 223 & 22,1 \\
\hline Restharngefühl & 190 & 18,8 \\
\hline Startverzögerung & 175 & 17,3 \\
\hline Nachtröpfeln & 167 & 16,5 \\
\hline Makrohämaturie & 76 & 7,5 \\
\hline Urgesymptomatik & 74 & 7,3 \\
\hline Überlaufinkontinenz & 42 & 4,2 \\
\hline rezid. Harnwegsinfekte & 39 & 3,9 \\
\hline Urgeinkontinenz & 33 & 3,3 \\
\hline Stressinkontinenz & 8 & 0,8 \\
\hline
\end{tabular}

Tabelle 10: Symptomatik 


\subsubsection{Miktionsfrequenz (präoperativ)}

Die folgenden Daten ergeben sich zum einen aus der Anamnese des aufnehmenden Arztes, zum anderen aus dem Fragebogen, der den Patienten im Rahmen der Verlaufsbeobachtung zugeschickt worden war.

\begin{tabular}{|l|l|l|l|l|}
\hline $\begin{array}{l}\text { Miktions- } \\
\text { frequenz }\end{array}$ & $\begin{array}{l}\text { Anzahl } \\
\text { tags }\end{array}$ & $\begin{array}{l}\text { in Prozent } \\
\text { (von 623) }\end{array}$ & $\begin{array}{l}\text { Anzahl } \\
\text { nachts }\end{array}$ & $\begin{array}{l}\text { in Prozent } \\
\text { (von 831) }\end{array}$ \\
\hline 9 & 124 & 19,9 & 14 & 1,7 \\
8 & 12 & 1,9 & 1 & 0,1 \\
\hline 7 & 73 & 11,7 & 16 & 1,9 \\
6 & 53 & 8,5 & 16 & 1,9 \\
\hline 5 & 113 & 18,3 & 53 & 6,4 \\
4 & 104 & 16,7 & 70 & 8,4 \\
3 & 113 & 18,1 & 170 & 20,7 \\
\hline 2 & 29 & 4,7 & 179 & 21,5 \\
1 & 2 & 0,3 & 193 & 23,2 \\
0 & 0 & 0 & 98 & 11,8 \\
\hline & 0 & 0 & 21 & 2,5 \\
\hline
\end{tabular}

Tabelle 11: Miktionsfrequenz (präoperativ)

Die Durchschnittswerte lagen tags bei 6,7 und nachts bei 3,4.

\subsubsection{Lebensqualität (präoperativ)}

In den Fragebögen, welche den Patienten zugesandt wurden, wurden die Patienten gebeten, ihre Lebensqualität vor und nach der Operation $\mathrm{zu}$ beurteilen. Dabei waren folgende Auswahlmöglichkeiten gegeben:

$0=$ ausgezeichnet

$1=$ zufrieden

$2=$ überwiegend zufrieden

$3=$ gemischt, teils zufrieden, teils unzufrieden

$4=$ überwiegend unzufrieden

$5=$ unglücklich

$6=$ sehr schlecht 
Von insgesamt 145 verwertbaren Antworten ergab sich folgende Verteilung für die präoperative Ausgangslage:

\begin{tabular}{|c|c|c|c|c|c|c|c|}
\hline $\begin{array}{l}\text { Lebens- } \\
\text { qualität }\end{array}$ & $\mathbf{0}$ & 1 & 2 & 3 & 4 & 5 & 6 \\
\hline Anzahl & 4 & 5 & 21 & 31 & 44 & 24 & 16 \\
\hline $\begin{array}{l}\text { in Prozent } \\
\text { (von 145) }\end{array}$ & 2,8 & 3,5 & 14,5 & 21,4 & 30,3 & 16,5 & 11,0 \\
\hline
\end{tabular}

Tabelle 12: Lebensqualität (präoperativ)

Der Durchschnitt lag bei einem Wert von 3,7.

\subsection{Präoperative Diagnostik}

Die Diagnostik wurde präoperativ jeweils durch rektale Palpation, durch laborchemische Untersuchungen (Urin und Serum) sowie apparativer Methoden (Sonographie, Stanzbiopsie, Auscheidungsurographie, Zystoskopie) durchgeführt.

\subsubsection{Digital-rektale Untersuchung (DRU)}

Bei 961 der Patienten $(95,1 \%$ der Gesamtzahl) wurde eine rektale Palpation der Prostata im Rahmen der körperlichen Eingangsuntersuchung von einem Arzt durchgeführt. Eine grosse Prostata konnte bei insgesamt 253 Patienten getastet werden, wobei davon 22 suspekt erschienen. Von insgesamt 628 mittelgrossen Prostatbefunden waren 48 auffällig, während bei 74 Patienten mit palpatorisch kleiner Prostata 6 suspekt waren.

\begin{tabular}{l|ll} 
Befund & Anzahl & $\begin{array}{l}\text { in Prozent } \\
\text { (von 961) }\end{array}$ \\
\hline gross, nicht suspekt & 231 & 24,0 \\
gross, suspekt & 22 & 2,3 \\
mittel, nicht suspekt & 580 & 60,4 \\
mittel, suspekt & 48 & 5,0 \\
klein, nicht suspekt & 74 & 7,7 \\
klein, suspekt & 6 & 0,6
\end{tabular}

Tabelle 13: Digital-rektale Untersuchung 


\subsubsection{Laborchemische Parameter}

Von laborchemischer Seite waren zum einen mögliche Harnwegsinfekte, Retentionswerte sowie der PSA-Wert als Hinweis für ein Malignom von Interesse.

\subsubsection{Urinuntersuchungen}

Bei dem Patientengut wurde präoperativ ein Urikult durchgeführt, dabei zeigten 152 Patienten (15,0\%) einen signifikanten Harnwegsinfekt mit mindestens 100000 Keimen pro ml Urin.

Eine Mikrohämaturie konnte bei 168 Patienten (16,6\%) nachgewiesen werden, 17 Patienten wiesen eine Makrohämaturie auf (1,7\%).

\subsubsection{Kreatinin}

Als stellvertretender Parameter für die Retentionswerte wurde bei insgesamt 982 Patienten der Kreatininspiegel im Serum bestimmt.

868 der Patienten $(88,4 \%)$ wiesen dabei Werte bis $1,4 \mathrm{mg} / \mathrm{dl}$ auf, 114 Fälle $(11,6 \%)$ lagen darüber, der Maximalwert betrug 5,7 mg/dl.

Der Durchschnittswert belief sich auf $1,1 \mathrm{mg} / \mathrm{dl}$.

\begin{tabular}{|c|c|c|c|c|c|c|c|c|c|c|}
\hline $\begin{array}{l}\text { Wert } \\
\text { in } \mathrm{mg} / \mathrm{dl}\end{array}$ & $\begin{array}{l}<1, \\
0\end{array}$ & $\begin{array}{l}<1, \\
2\end{array}$ & $\begin{array}{l}<1 \\
4\end{array}$ & $\begin{array}{l}<1 \\
6\end{array}$ & $\begin{array}{l}<1 \\
8\end{array}$ & $\begin{array}{l}<2, \\
0\end{array}$ & $\begin{array}{l}<2, \\
2\end{array}$ & $\begin{array}{l}<2 \\
4\end{array}$ & $\begin{array}{l}<2, \\
6\end{array}$ & $\begin{array}{l}>2 \\
6\end{array}$ \\
\hline Anzahl & 489 & 263 & 116 & 54 & 19 & 22 & 3 & 1 & 4 & 11 \\
\hline in $\%$ & 49,8 & 26,8 & 11,8 & 5,5 & 1,9 & 2,2 & 0,3 & 0,1 & 0,4 & 1,1 \\
\hline
\end{tabular}

Tabelle 14: Kreatinin

\subsubsection{Prostata spezifisches Antigen (PSA)}

Um einen möglichen Hinweis auf die Dignität des postoperativen histologischen Ergebnisses zu erhalten, wurde bei 979 der Patienten (96,8\% der Gesamtfälle) der präoperative PSA-Wert bestimmt.

Dabei zeigten 455 Patienten (46,5\%) Werte kleiner 4,0 ng/ml, 319 lagen zwischen 4,0 und 10,0 $\mathrm{ng} / \mathrm{ml}(32,6 \%)$, die übrigen 205 Patienten lagen mit ihren Werten über 10,0 ng/ml (20,9\%).

Im Mittel lag der PSA-Wert bei 6,25 ng/ml, der Medianwert bei

$4,4 \mathrm{ng} / \mathrm{ml}$. Betrachtete man nur die Fälle mit reiner Hyperplasie ohne Malignität, ergab sich ein Durchschnittswert von $5,8 \mathrm{ng} / \mathrm{ml}$. 


\begin{tabular}{l|ll} 
PSA-Wert & Anzahl & in Prozent (von 979) \\
\hline $0-1,9$ & 223 & 22,8 \\
$2,0-3,9$ & 232 & 23,7 \\
$4,0-5,9$ & 156 & 15,9 \\
$6,0-7,9$ & 103 & 10,5 \\
$8,0-9,9$ & 60 & 6,2 \\
$10,0-11,9$ & 59 & 6,0 \\
$12,0-13,9$ & 37 & 3,8 \\
$14,0-15,9$ & 31 & 3,2 \\
$16,0-17,9$ & 19 & 1,9 \\
$18,0-19,9$ & 19 & 1,9 \\
20,0 und mehr & 40 & 4,1
\end{tabular}

Tabelle 15: Prostata spezifisches Antigen

\subsubsection{Sonographie}

Sonographisch wurden zum einen mittels Abdomensonographie die Nieren hinsichtlich eines Harnaufstaus beurteilt sowie der Restharn bestimmt, zum anderen wurde durch einen transrektalen Ultraschall (TRUS) das Gesamtgewicht der Prostata sowie das Adenomgewicht ermittelt.

\subsubsection{Sonographie der Nieren}

Bei der Sonographie der Nieren zeigte sich bei 896 Patienten $(88,6 \%)$ ein unauffälliger Befund, eine Hydronephrose Grad I konnte bei 75 Patienten (7,4\%) beobachtet werden, 29 Patienten $(2,9 \%)$ wiesen eine II.-gradige Hydronephrose auf, während sich 11 Patienten $(1,1 \%)$ bereits im Stadium III befanden.

\begin{tabular}{lllllllllll} 
Stadium & 0 & I & \multicolumn{3}{c}{ II } & \multicolumn{5}{c}{ III } \\
Seite & & re & li & bds & re & li & bds & re & li & bds \\
Anzahl & 896 & 46 & 51 & 22 & 22 & 14 & 7 & 5 & 7 & 1 \\
Prozent & 88,6 & 4,6 & 5,1 & 2,2 & 2,2 & 1,4 & 0,7 & 0,5 & 0,7 & 0,1 \\
Tabelle 16: & Sonographie der Nieren
\end{tabular}




\subsubsection{Restharn}

Bei der sonographisch bestimmten Menge des Restharns präoperativ ergab sich bei insgesamt 688 Ergebnissen folgende Verteilung:

\begin{tabular}{l|ll}
$\begin{array}{l}\text { Restharn } \\
\text { in } \mathbf{~ m l ~}\end{array}$ & Anzahl & $\begin{array}{l}\text { in Prozent } \\
\text { (von 683) }\end{array}$ \\
0 & 38 & 5,5 \\
$1-100$ & 50 & 7,3 \\
$101-200$ & 149 & 21,7 \\
$201-300$ & 140 & 20,3 \\
$301-400$ & 76 & 11,1 \\
$401-500$ & 91 & 13,2 \\
$501-600$ & 52 & 7,6 \\
$601-700$ & 26 & 3,8 \\
$701-800$ & 37 & 5,3 \\
$801-900$ & 21 & 3,0 \\
$901-1000$ & 4 & 0,6 \\
$>1000$ & 4 & 0,6
\end{tabular}

Tabelle 17: Restharn

Der durchschnittliche Restharn betrug 317,6 ml, der Medianwert lag bei $280 \mathrm{ml}$.

\subsubsection{Transrektaler Ultraschall (TRUS)}

Durch den transrektalen Ultraschall war es möglich, das Gesamtgewicht der Prostata zu ermitteln. Bei insgesammt 696 untersuchten Patienten lagen 540 bei einem Gewicht zwischen 41 und 100 Gramm (77,6\%). Das mittlere Gesamtgewicht betrug 67 Gramm, Medianwert 66 Gramm.

\begin{tabular}{|l|l|l|}
\hline Gesamtgewicht in gr & Anzahl & $\begin{array}{l}\text { in Prozent } \\
\text { (von 696) }\end{array}$ \\
\hline $0-20$ & 14 & 2,0 \\
$21-40$ & 78 & 11,2 \\
$41-60$ & 208 & 29,9 \\
$61-80$ & 194 & 27,9 \\
$81-100$ & 138 & 19,8 \\
$101-120$ & 36 & 5,2 \\
$121-140$ & 19 & 2,7 \\
$>140$ & 9 & 1,3 \\
\hline
\end{tabular}

Tabelle 18: Transrektaler Ultraschall (Gesamtgewicht) 


\subsubsection{Adenomgewicht}

Ein weiteres sonographisches Diagnostikum war die Bestimmung des Gewichtes des hyperplastischen Gewebes innerhalb der Prostata.

Untersucht wurden diesbezüglich 548 Patienten.

Dabei hatten 438 Patienten (79,9\%) ein Adenomgewicht zwischen 11 und 60 Gramm. Der Mittelwert belief sich auf 40,9 Gramm.

\begin{tabular}{|l|l|l|}
\hline Adenomgewicht & Anzahl & $\begin{array}{l}\text { in Prozent } \\
\text { (von 548) }\end{array}$ \\
\hline $0-10$ & 12 & 2,2 \\
$11-20$ & 88 & 16,1 \\
$21-30$ & 96 & 17,6 \\
$31-40$ & 112 & 20,4 \\
$41-50$ & 79 & 14,4 \\
$51-60$ & 63 & 11,5 \\
$61-70$ & 35 & 6,4 \\
$71-80$ & 29 & 5,3 \\
$81-90$ & 14 & 2,5 \\
$91-100$ & 10 & 1,8 \\
$>100$ & 10 & 1,8 \\
\hline
\end{tabular}

Tabelle 19: Transrektaler Ultraschall (Adenomgewicht)

Bei insgesamt 691 Angaben bzgl. der sonographisch vermuteten Dignität war in 618 Fällen $(89,4 \%)$ die P-Zone unauffällig,

45 Patienten wiesen eine suspekte rechte P-Zone auf (6,5\%), während bei 41 die linke Seite auffällig war $(5,9 \%)$.

Ein verdächtiger beidseitiger Befund wurde bei 13 Patienten (1,9\%) erhoben.

\subsubsection{Invasive Diagnostik}

Bei unklarer präoperativer Dignität, sei dies durch einen suspekten Tastbefund oder eine Erhöhung des PSA-Wertes, wurde bei 187 Patienten eine Stanzbiopsie entnommen. 167 Biopsien davon $(89,3 \%)$ wurden in der urologischen Klinik des Klinikum rechts der Isar ultraschall gesteuert durchgeführt, 15 auswärts ultraschall gesteuert $(8,0 \%)$ sowie weitere 5 Stanzbiopsien auswärts unter digitaler-rektaler Kontrolle (2,7\%).

In der histologischen Aufarbeitung handelte es sich in 181 Fällen um eine benigne Prostatahyperplasie (96,8\%), 9 Patienten wiesen ein Prostatakarzinom auf $(4,8 \%)$, in weiteren 8 Fällen zeigte sich eine PIN (4,3\%). Desweiteren zeigte sich bei 91 Patienten eine chronische Prostatitis (48,7\%) und in 7 Fällen eine chronisch granulomatöse Prostatitis $(3,7 \%)$. 


\begin{tabular}{l|l|l|}
$\begin{array}{l}\text { Histologischer } \\
\text { Befund }\end{array}$ & Anzahl & $\begin{array}{l}\text { in Prozent } \\
\text { (von 187) }\end{array}$ \\
\hline $\begin{array}{l}\text { BPH } \\
\text { Karzinom }\end{array}$ & 181 & 96,8 \\
\hline $\begin{array}{l}\text { PIN } \\
\text { chron. Prostatitis } \\
\text { chron. granulomatöse } \\
\text { Prostatitis }\end{array}$ & 9 & 4,8 \\
\hline $\begin{array}{l}\text { Tabell } \\
\text { M }\end{array}$ & 7 & 4,3 \\
\hline
\end{tabular}

Tabelle 20: Histologie/Diagnostik

\subsubsection{Ausscheidungsurogramm}

Zur röntgenologischen Darstellung der Harnwege wurde bei 803 Patienten ein Ausscheidungsurogramm durchgeführt.

Hierbei zeigte sich bei 346 Patienten eine Anhebung des Blasenbodens, 75 Patienten wiesen ein Korbhenkelphänomen auf. Bei 42 Darstellungen konnten Blasendivertikel nachgewiesen werden, 33 zeigten das Bild einer Stauung. Des weiteren sah man in 23 Fällen Kontrastmittelaussparungen, 7 mal Ureter fissus, 2 mal Ureter duplex sowie 6 weitere Doppelnieren. Bei 267 Patienten ergab das Ausscheidungsurogramm einen unauffälligen Befund.

\begin{tabular}{|c|c|c|}
\hline Befund & Anzahl & $\begin{array}{l}\text { in Prozent } \\
\text { (von 803) }\end{array}$ \\
\hline Anhebung Blasenboden & 346 & 43,1 \\
\hline Korbhenkelphänomen & 75 & 9,3 \\
\hline Blasendivertikel & 42 & 5,2 \\
\hline Stauung & 33 & 4,1 \\
\hline Aussparung & 23 & 2,8 \\
\hline Ureter fissus & 7 & 0,9 \\
\hline Doppelniere & 6 & 0,8 \\
\hline Ureter duplex & 2 & 0,3 \\
\hline Hydronephrose & 2 & 0,3 \\
\hline unauffällig & 267 & 33,2 \\
\hline
\end{tabular}

Tabelle 21: Ausscheidungsurogramm

\subsubsection{Zystoskopie}

Von insgesamt 1000 verwertbaren Datensätzen wurde bei 187 Fällen eine Zystoskopie im Rahmen der präoperativen Abklärung durchgeführt, 69 davon in der urologischen Klinik der Klinik rechts der Isar, 118 dagegen auswärts.

Leider wurde nicht zu jedem Diagnosepunkt Stellung genommen, so dass die einzelnen Gesamtsummen etwas differieren.

In der folgenden Tabelle sind die Ergebnisse aufgeführt: 


\begin{tabular}{|l|l|l|l|l|l|}
\hline Diagnose & gesamt & ja & in \% & nein & in\% \\
\hline Harnröhre auffällig & 155 & 34 & 21,9 & 121 & 78,1 \\
\hline $\begin{array}{l}\text { Seitenlappen voluminös } \\
\text { Mittellappen voluminös }\end{array}$ & 153 & 82 & 53,6 & 71 & 46,4 \\
\hline hohe Querbarre & 161 & 48 & 31,2 & 106 & 68,8 \\
\hline Divertikel & 162 & 18 & 9,9 & 145 & 90,1 \\
\hline Balkenbildung & 164 & 77 & 46,9 & 87 & 53,1 \\
\hline Blasenhalsenge & 160 & 19 & 11,9 & 141 & 88,1 \\
Harnröhrenenge & 159 & 16 & 10,1 & 143 & 89,9 \\
\hline Meatusenge & 158 & 2 & 1,3 & 156 & 98,7 \\
Blasentumor & 167 & 11 & 6,6 & 156 & 93,4 \\
\hline Pseudodivertikel & 160 & 15 & 9,4 & 145 & 90,6 \\
Steine & 164 & 22 & 12,3 & 142 & 87,7
\end{tabular}

Tabelle 22: Zystoskopie

\subsubsection{Indikation}

Aus der Anamnese und dem Ergebnis der Voruntersuchungen ergab sich nun für jeden Patienten eine individuelle Indikation für den operativen Eingriff, wobei die obstruktiven Miktionsbeschwerden mit 953 Angaben das Feld anführten (94,3\% bei 1011 Patienten); auch Mehrfachangaben waren möglich.

\begin{tabular}{|c|c|c|}
\hline Indikation & Anzahl & $\begin{array}{l}\text { in Prozent } \\
\text { (von 1011) }\end{array}$ \\
\hline obstruktive & 953 & 94,3 \\
\hline $\begin{array}{l}\text { Miktionsbeschwerden } \\
\text { irritative } \\
\text { Miktionsbeschwerden }\end{array}$ & 170 & 16,8 \\
\hline Harnverhalt & 217 & 21,5 \\
\hline Hydronephrose I & 20 & 2,0 \\
\hline Hydronephrose II & 13 & 1,3 \\
\hline Hydronephrose III & 6 & 0,6 \\
\hline Restahrn $>100 \mathrm{ml}$ & 84 & 8,3 \\
\hline Makrohämaturie & 33 & 3,3 \\
\hline $\begin{array}{l}\text { rezidivierender } \\
\text { Harnwegsinfekt }\end{array}$ & 27 & 2,7 \\
\hline Prostatitis & 4 & 0,4 \\
\hline
\end{tabular}

Tabelle 23: Indikation 


\subsubsection{Präoperative Diagnose}

Aus der Gesamtheit der Vorbefunde und der Untersuchungsergebnisse liess sich somit für jeden Patienten eine Diagnose stellen, wobei auch hier Mehrfachnennungen möglich waren. Die Diagnose benigne Prostatahyperplasie wurde bei 996 der 1011 Patienten (98,5\%) gestellt, eine Harnröhrenenge hatten 23 der Patienten $(2,3 \%)$, ein Prostatakarzinom 36 Patienten $(3,6 \%)$ und 11 Patienten litten an einer Blasenhalsenge $(1,1 \%)$.

\begin{tabular}{l|ll|} 
Diagnose & Anzahl & $\begin{array}{l}\text { in Prozent } \\
\text { (von 1011) }\end{array}$ \\
\hline BPH & 996 & 98,5 \\
Prostatakarzinom & 36 & 3,6 \\
\hline $\begin{array}{l}\text { Harnröhrenenge } \\
\text { Blasenhalsenge }\end{array}$ & 23 & 2,3 \\
\hline
\end{tabular}

Tabelle 24: Präoperative Diagnose

Die Kombination der Diagnosen BPH und Harnröhrenenge ergab sich 22 mal, BPH zusammen mit Blasenhalsenge 10 mal, während beim Prostatakarzinom immer auch eine benigne Prostatahyperplasie auftrat (36 Fälle).

\subsection{Perioperativer Verlauf}

In Hinsicht auf den perioperativen Verlauf wurden verschiedene Kriterien wie Operations-Zeit, Narkoseverfahren, Menge der Spülflüssigkeit, Zusatzeingriffe, Resektionsgewicht, histologischer Befund, DK-Verweildauer, Hospitalisationszeit sowie Hämoglobin- und Natriumwert ermittelt.

\subsubsection{Operations-Zeit}

Die durchschnittliche Operationszeit lag bei knapp 70 Minuten (69,7 min), wobei dieser Faktor bei 986 der 1011 Patienten ermittelt werden konnte (97,5\%), der Median lag bei 69 Minuten. Die kürzeste Operation dauerte 10 Minuten, der längste Eingriff 210 Minuten. Berücksichtigt wurden alle im Anästhesieblatt festgehaltenen Werte unter Einschluss von Begleitoperationen während der gleichen Sitzung. 


\begin{tabular}{l|ll}
$\begin{array}{l}\text { OP-Zeit } \\
\text { (in Minuten) }\end{array}$ & Anzahl & $\begin{array}{l}\text { in Prozent } \\
\text { (von 986) }\end{array}$ \\
\hline $0-19$ & 6 & 0,6 \\
$20-39$ & 119 & 12,1 \\
$40-59$ & 246 & 25,0 \\
$60-79$ & 266 & 27,0 \\
$80-99$ & 164 & 16,6 \\
$100-119$ & 81 & 8,2 \\
$120-139$ & 74 & 7,5 \\
$140-159$ & 18 & 1,8 \\
$160-179$ & 5 & 0,5 \\
$180-199$ & 5 & 0,5 \\
200 und mehr & 2 & 0,2
\end{tabular}

Tabelle 24: Operationszeit

\subsubsection{Anästhesieverfahren}

Für den operativen Eingriff standen prinzipiell drei verschiedene Anästhesieverfahren zu Verfügung, wobei bezüglich des Risikoprofils des einzelnen Patienten das für ihn geeignetste gewählt wurde.

Bei insgesamt 987 registrierten Fällen wurde die Operation bei 872 Patienten in Spinalanästhesie $(87,6 \%)$ und bei 115 in Intubationsnarkose durchgeführt (11,6\%).

\begin{tabular}{l|l|l|}
\hline $\begin{array}{l}\text { Anästhesieverfahren } \\
\text { Anzahl }\end{array}$ & $\begin{array}{l}\text { in Prozent } \\
\text { (von 987) }\end{array}$ \\
\hline Spinalanästhesie & 872 & 88,4 \\
ITN & 115 & 11,6
\end{tabular}

Tabelle 25: Anästhesieverfahren 


\subsubsection{Spülflüssigkeit}

Die bei der Operation verwendete Menge an Spülflüssigkeit konnte bei 229 Patienten erfasst werden. Die durchschnittliche Menge lag dabei bei 21,6 Litern, der Minimalwert betrug $5000 \mathrm{ml}$, der Maximalwert lag bei 80 Litern.

\begin{tabular}{l|l|l|}
$\begin{array}{l}\text { Menge } \\
\text { (in ml) }\end{array}$ & Anzahl & $\begin{array}{l}\text { in Prozent } \\
\text { (von 229) }\end{array}$ \\
$0-5000$ & 3 & 1,3 \\
$5001-10000$ & 20 & 8,7 \\
$10001-15000$ & 60 & 26,2 \\
$15001-20000$ & 59 & 25,8 \\
$20001-25000$ & 41 & 17,9 \\
$25001-30000$ & 24 & 10,5 \\
$30001-35000$ & 11 & 4,8 \\
$35001-40000$ & 4 & 1,7 \\
40001 und mehr & 7 & 3,1
\end{tabular}

Tabelle 26: Spülflüssigkeit

\subsubsection{Zusatzeingriffe}

Neben der TURP waren bei dem Patientengut noch insgesamt 558 weitere Eingriffe nötig, wobei bei manchen Patienten 2 oder auch mehr Begleitoperationen durchgeführt werden mussten.

Bei 242 Patienten $(24,0 \%)$ wurde eine Blasenhalskerbung durchgeführt, eine Urethrotomia interna nach Otis war 233 mal nötig $(23,1 \%)$, nach Sachse 53 mal $(5,2 \%)$. Des weiteren war in 10 Fällen eine Meatotomie (1,0\%) erforderlich, bei 6 Patienten wurde eine Circumcision durchgeführt $(0,6 \%)$. Bei 14 Patienten musste intraoperativ ein suprapubischer Blasenkatheter angelegt werden $(1,4 \%)$.

\begin{tabular}{|c|c|c|}
\hline Begleiteingriff & Anzahl & $\begin{array}{l}\text { in Prozent } \\
\text { (von 1011) }\end{array}$ \\
\hline Blasenhalskerbung & 242 & 24,0 \\
\hline Urethrotomie (Otis) & 233 & 23,1 \\
\hline Urethrotomie (Sachse) & 53 & 5,2 \\
\hline Meatotomie & 10 & 1,0 \\
\hline Circumcision & 6 & 0,6 \\
\hline $\begin{array}{l}\text { suprapubischer } \\
\text { Blasenkatheter }\end{array}$ & 14 & 1,4 \\
\hline
\end{tabular}

Tabelle 27: Zusatzeingriffe 


\subsubsection{Resektionsgewicht}

Bei insgesamt 994 erfassten Fällen lagen 79,2\% der Patienten bei einem Resektionsgewicht von kleiner gleich 50 Gramm. Das maximal resezierte Gewicht lag bei 120 Gramm.

Das durchschnittliche Resektionsgewicht lag bei 35,4 Gramm.

\begin{tabular}{|l|l|l|}
$\begin{array}{l}\text { Resektionsgewicht } \\
\text { (in Gramm) }\end{array}$ & Anzahl & $\begin{array}{l}\text { in Prozent } \\
\text { (von 994) }\end{array}$ \\
\hline $0-20$ & 270 & 27,2 \\
$21-40$ & 380 & 38,2 \\
$41-60$ & 207 & 20,8 \\
$61-80$ & 91 & 9,2 \\
$81-100$ & 35 & 3,5 \\
$101-120$ & 11 & 1,1
\end{tabular}

Tabelle 28: Resektionsgewicht

\subsubsection{Histologischer Befund}

Das Ergebnis der histologischen Aufarbeitung lag in 948 Fällen vor.

Dabei zeigte sich eine benigne Prostatahyperplasie bei 942 Patienten $(99,4 \%)$, eine Prostatitis bei 346 Auswertungen (36,5\%).

Ein Prostatakarzinom liess sich in 52 Fällen nachweisen, bei 21 Patienten eine PIN (2,2\%).

\begin{tabular}{l|ll} 
Histologie & Anzahl & $\begin{array}{l}\text { in Prozent } \\
\text { (von 948) }\end{array}$ \\
BPH & 942 & 99,4 \\
Prostatitis & 346 & 36,5 \\
Karzinom & 52 & 5,5 \\
PIN & 21 & 2,2
\end{tabular}

Tabelle 29: Histologischer Befund

Nach Abzug der histologisch gesicherten Carcinome ergab sich natürlich eine neue Verteilung der PSA-Werte bei der präoperativen Diagnostik. Der Durchschnittswert sank von 6,25 ng/ml auf 5,81 ng/ml, während der Medianwert von 4,4 $\mathrm{ng} / \mathrm{ml}$ auf 4,9 $\mathrm{ng} / \mathrm{ml}$ anstieg (da doch viele Carcinome mit relativ kleinen PSA-Werten auftraten). 


\subsubsection{Dauerkatheter}

Im Hinblick auf die postoperative Betreuung der Patienten während des weiteren stationären Aufenthaltes wurde die Liegezeit des intraoperativ gelegten Dauerkatheters in 980 Fällen erfasst. Die durchschnittliche Katheterverweildauer betrug 2,2 Tage, die Spanne reichte von 1 Tag bis zu 35 Tagen. Insgesamt hatten jedoch 89,6\% den Dauerkatheter für max. 2 Tage liegen.

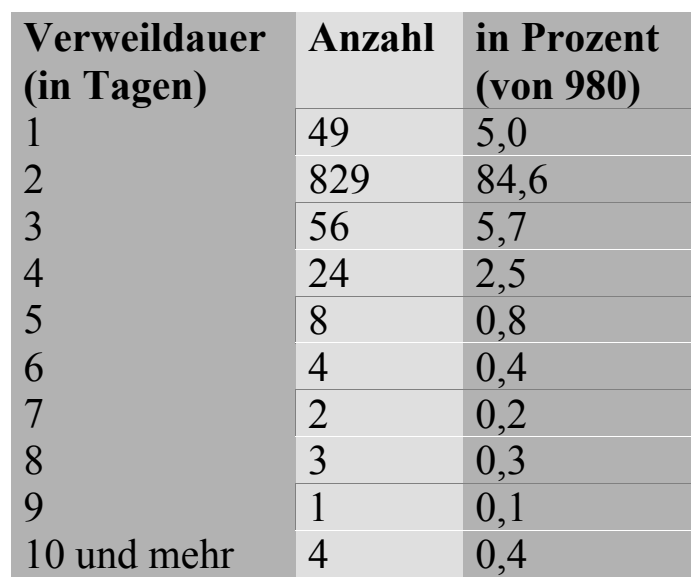

Tabelle 30: Dauerkatheter (Verweildauer)

\subsubsection{Hämoglobinwerte und Bluttransfusionen}

Um eine Aussage über einen möglichen Blutverlust bei der Operation treffen zu können, wurde der Hämoglobingehalt sowohl prä- als auch postoperativ gemessen. Der Hb-Wert konnte bei 999 Patienten vor dem Eingriff (98,8\%) und bei 997 Patienten (98,6\%) postoperativ ermittelt werden. Dabei betrug der durchschnittliche Wert präoperativ 14,9 g/dl, die Werte rangierten zwischen $8,8 \mathrm{~g} / \mathrm{dl}$ und $19,8 \mathrm{~g} / \mathrm{dl}$.

Postoperativ zeigten sich Hämoglobin - Werte zwischen 6,7 g/dl und 19,0 g/dl, der Durchschnittswert betrug 13,3 g/dl.

\begin{tabular}{|c|c|c|c|c|}
\hline Hb-Wert & $\begin{array}{l}\text { prä-op } \\
\text { (Anzahl) }\end{array}$ & $\begin{array}{l}\text { prä-op } \\
\text { (\% von 999) }\end{array}$ & $\begin{array}{l}\text { post-op } \\
\text { (Anzahl) }\end{array}$ & $\begin{array}{l}\text { post-op } \\
\text { (\% von 997) }\end{array}$ \\
\hline bis 10,0 & 0 & 0 & 62 & 6,2 \\
\hline $10,1-12,0$ & 54 & 5,4 & 242 & 24,2 \\
\hline $12,1-14,0$ & 248 & 24,8 & 401 & 40,1 \\
\hline $14,1-16,0$ & 530 & 53,0 & 250 & 25,0 \\
\hline $16,1-18,0$ & 157 & 15,7 & 29 & 2,9 \\
\hline $18,1-20$ & 10 & 1,0 & 3 & 0,3 \\
\hline
\end{tabular}

Tabelle 31: Hämoglobinwert 
Dabei wurden intraoperativ bei 98 (9,8\%) von 997 erfassten Patienten Erythrozytenkonzentrate (EK) transfundiert. Ein EK war bei 21 (2,1\%) Patienten nötig, bei 72 (7,2\%) Patienten wurden 2 EK verabreicht, während 4 Konserven bei $4(0,4 \%)$ Patienten und 5 Konserven bei einem $(0,1 \%)$ Patienten gegeben wurden.

Postoperativ kam es bei $50(5,0 \%)$ von 986 erfassten Patienten zu Transfusionen, wobei eine Konserve bei $9(0,9 \%)$ Patienten, zwei Konserven bei $33(3,3 \%)$ und vier Konserven bei 8 $(0,8 \%)$ Patienten gegeben wurden.

Insgesamt erhielten 137 Patienten (13,7 \%) Blutransfusionen.

\begin{tabular}{l|l|l|l|l|l|l|} 
EK-Gabe & $\mathbf{0}$ & $\mathbf{1}$ & $\mathbf{2}$ & $\mathbf{3}$ & $\mathbf{4}$ & $\mathbf{5}$ \\
\cline { 2 - 7 } intra-op & 899 & 21 & 72 & 0 & 4 & 1 \\
post-op & 936 & 9 & 33 & 0 & 8 & 0
\end{tabular}

Tabelle 32: Transfusionen

\subsubsection{Natrium-Wert}

Als Mass für die Einschwemmung wurde bei der stationären Aufnahme sowie postoperativ der Natrium-Wert im Serum gemessen.

Dabei rangierten die präoperativen Werte zwischen $107 \mathrm{mmol} / 1$ und $171 \mathrm{mmol} / \mathrm{l}$, der Durchschnittswert lag bei $139 \mathrm{mmol} / \mathrm{l}$, wobei insgesamt 976 Patienten erfasst wurden.

In der postoperativen Kontrolle bei 606 Patienten ergaben sich Natrium-Werte von 109 mmol/1 bis $148 \mathrm{mmol} / \mathrm{l}$ und einem Durchschnitt von $136 \mathrm{mmol} / \mathrm{l}$.

\begin{tabular}{|c|c|c|c|c|}
\hline Na-Wert & $\begin{array}{l}\text { prä-op } \\
\text { (von 976) }\end{array}$ & $\begin{array}{l}\text { prä-op } \\
\text { (in \%) }\end{array}$ & $\begin{array}{l}\text { post-op } \\
\text { (von 606) }\end{array}$ & $\begin{array}{l}\text { post-op } \\
\text { (in \%) }\end{array}$ \\
\hline$<110$ & 1 & 0,1 & 1 & 0,2 \\
\hline 110-119 & 7 & 0,7 & 11 & 1,8 \\
\hline $120-129$ & 30 & 3,1 & 48 & 7,9 \\
\hline 130-139 & 493 & 50,5 & 437 & 72,1 \\
\hline $140-149$ & 442 & 45,3 & 109 & 18,0 \\
\hline $150-159$ & 2 & 0,2 & 0 & 0 \\
\hline$>159$ & 1 & 0,1 & 0 & 0 \\
\hline
\end{tabular}

Tabelle 33: Natrium-Werte

Eine Natrium-Substitution wurde bei 79 (7,9\%) von 996 ermittelten Patienten durchgeführt, bei 917 (92,1\%) war keine derartige Therapie nötig. 


\subsection{Komplikationen}

Die aufgetretenen Komplikationen werden im folgenden in intraoperative, allgemeine, Früh- und Spätkomplikationen unterteilt.

\subsubsection{Intraoperative Komplikationen}

Bei den 998 erfassten Patienten kam es bei 19 (1,9\%) zu einer beschriebenen Sinuseröffnung und bei $7(0,7 \%)$ Patienten zu einer Unterfahrung.

Ein TUR-Syndrom erlitten $3(0,3 \%)$ Patienten. Bei $14(1,4 \%)$ Patienten kam es zu einer gravierenden Blutung. Eine Blasenperforation trat bei $4(0,4 \%)$ Patienten auf, eine Prostatakapselperforation bei $14(1,4 \%)$.

Insgesamt kam es also bei $61(6,1 \%)$ Patienten zu einer intraoperativen, operationsspezifischen Komplikation.

\begin{tabular}{l|l|l|} 
Komplikation & Anzahl & in \% (von 998) \\
\hline Sinuseröffnung & 19 & 1,9 \\
\hline TUR-Syndrom & 3 & 0,3 \\
\hline Unterfahrung & 7 & 0,7 \\
\hline $\begin{array}{l}\text { Blasenperforation } \\
\text { Prostatakapselperforation }\end{array}$ & 4 & 0,4 \\
\hline $\begin{array}{l}\text { Blutung } \\
\text { Todesfall }\end{array}$ & 14 & 1,4 \\
gesamt & 0 & 1,4 \\
\hline Tabell & 61 & 0 \\
\hline
\end{tabular}

Tabelle 34: Intraoperative Komplikationen

\subsubsection{Allgemeine Komplikationen}

Als operationsunspezifische Komplikation war es bei $6(0,6 \%)$ Patienten zu einer Pneumonie gekommen, zwei $(0,2 \%)$ erlitten eine Herzinsuffizienz, bei einem $(0,1 \%)$ Patient trat ein Apoplex auf, bei einem weiteren wurde eine Lungenembolie festgestellt.

Die Rate der allgemeinen Komplikationen lag somit bei 1,0\% (10 Patienten von 998 auswertbaren Fällen)

\begin{tabular}{l|l|l|} 
Komplikation & Anzahl & in \% (von 998) \\
\hline $\begin{array}{l}\text { Pneumonie } \\
\text { Herzinsuffizienz }\end{array}$ & 6 & 0,6 \\
Lungenembolie & 1 & 0,2 \\
Apoplex & 1 & 0,1 \\
gesamt & 10 & 0,1 \\
\hline
\end{tabular}

Tabelle 35: Allgemeine Komplikationen 


\subsubsection{Frühkomplikationen}

Als Komplikationen der Frühphase wurden folgende Kriterien erfasst: Nachblutung und Blasentamponade mit Revision, Harnverhalt, Restharnbildung, Nachresektion sowie Entzündungen (Harnwegsinfekt, Urethritis und Nebenhodenentzündung).

Bei insgesamt 1003 erfassten Fällen kam es bei 151 Patienten zu Frühkomplikationen (15,1\%).

\subsubsection{Nachblutung}

$\mathrm{Zu}$ Nachblutungen kam es im gesamten Patientengut bei 42 (4,2\%) Fällen; sie traten überwiegend vom Operationstag bis zum dritten postoperatven Tag auf, nur einmal zeigte sich eine spätere Nachblutung (6. postoperativer Tag). Durchschnittlich fand die Nachblutung 1,4 Tage postoperativ statt.

Eine Nachkoagulation wurde bei 22 Patienten durchgeführt.

22 Patienten $(2,2 \%)$ wiesen eine Blasentamponade auf, welche wie folgt revidiert wurde: Tamponadenausräumung über einen Dauerkatheter bei 5 Patienten $(0,5 \%)$ sowie über ein Zystoskop bei 13 Patienten (1,3\%), Wiener Zug bei 2 Patienten (0,2\%), eine Sectio alta war bei 2 Patienten nötig $(0,2 \%)$.

\begin{tabular}{l|l|l|} 
Revision & Anzahl & in \% (von 1003) \\
über Dauerkatheter & 5 & 0,5 \\
über Zystoskop & 13 & 1,3 \\
\hline $\begin{array}{l}\text { Wiener Zug } \\
\text { Sectio alta }\end{array}$ & 2 & 0,2 \\
gesamt & 2 & 0,2 \\
\hline & 22 & 2,2
\end{tabular}

Tabelle 36: Revision bei Nachblutung

\subsubsection{Restharnbildung und Harnverhalt}

Zur Restharnbildung über $100 \mathrm{ml}$ kam es bei 29 der erfassten Fälle (2,9\%), dabei zeigten sich Restharnmengen von 100 bis $1100 \mathrm{ml}$. Der Durchschnittswert lag bei $350 \mathrm{ml}$, der Medianwert bei $300 \mathrm{ml}$.

Einen Harnverhalt wiesen 73 (7,3\%) aller Patienten auf, in 46 Fällen (4,6\%) wurde ein Dauerkatheter eingelegt, bei 27 Patienten (2,7\%) war die Anlage einer suprapubischen Harnableitung nötig. 


\subsubsection{Nachresektion}

Eine Nachresektion wurde bei 51 Patienten $(5,1 \%)$ durchgeführt. Dabei bestand die Indikation bei 14 Patienten in einer Nachblutung, 34 Patienten wiesen persistierende Miktionsbeschwerden auf.

Das Resektionsgewicht hatte dabei Werte von 1 Gramm bis 50 Gramm, durchschnittlich wurden 15,7 Gramm reseziert.

\subsubsection{Entzündungen}

Im postoperativen Verlauf kam es bei 38 Patienten $(3,8 \%)$ zu einem nachgewiesenen Harnwegsinfekt, bei 2 Patienten $(0,2 \%)$ trat eine Nebenhodenentzündung auf, während eine Urthritis nicht beobachtet wurde.

Die Harnwegsinfekte traten überwiegend zwischen dem 1. und 7. postoperativen Tag auf, durchschnittlich 3,8 Tage postoperativ.

\begin{tabular}{l|l|l|} 
Entzündung & Anzahl & in \% (von 1003) \\
\hline Harnwegsinfekt & 38 & 3,8 \\
Epididymitis & 2 & 0,2 \\
Urethritis & 0 & 0 \\
gesamt & 40 & 4,0
\end{tabular}

Tabelle 37: Entzündungen (postoperativ)

\subsubsection{Spätkomplikationen}

Bei den Spätkomplikationen wurden folgende Parameter ermittelt:

Blutung, Blasenhalsenge, Harnröhrenstriktur, Epididymitis, Inkontinenz und Impotenz. Insgesamt kam es bei 114 (11,4\%) von 996 Patienten zu Spätkomplikationen.

\subsubsection{Blutung}

In 21 Fällen (2,1\%) kam es zu einer Blutung, wovon bei 13 Patienten die Revision über einen Spülkatheter erfolgte (durchschnittlich nach 17,1 Tagen), eine zystoskopische Hämatomausräumung wurde bei 2 Patienten durchgeführt (im Durchschnitt nach 18,5 Tagen). Eine Koagulation bzw. Nachresektion war bei 4 Patienten nötig (nach 11,5 Tagen im Durchschnitt).

In 15 Fällen war die Nachblutung Hämoglobin-wirksam (1,5\%), wobei bei 6 Patienten Bluttransfusionen durchgeführt wurden $(0,6 \%)$. 


\subsubsection{Blasenhalsenge und Harnröhrenstriktur}

Als eingriffsspezifische Komplikationen wurden auch die Blasenhalsenge und die Harnröhrenstriktur erfasst.

Eine Blasenhalsenge wurde bei 14 Patienten festgestellt (1,4\%), wobei der Zeitraum zwischen Operation und Diagnosestellung zwischen 119 Tagen und 1312 Tagen rangierte; der Durchschnitt lag bei 612 Tagen.

$\mathrm{Zu}$ einer Harnröhrenstriktur kam es bei 12 Patienten (1,2\%). Dabei vergingen zwischen 57 und 1583 Tage von der Operation bis zur Diagnosestellung, durchschnittlich 581,4 Tage (Medianwert 393 Tage).

Eine Korrektur war bei 11 Patienten nötig; teilweise waren zwei Revisionen nötig, so dass sich eine Anzahl von 14 Korrekturen ergab.

Bei 2 Patienten wurde eine Bougierung durchgeführt, bei 8 Patienten eine Urethrotomia interna (5 mal nach Sachse, 3 mal nach Otis). Ein Stent wurde bei 3 Patienten eingebracht, bei einem Patienten kam eine Meatotomie zur Anwendung.

\begin{tabular}{l|l|l|}
\hline & Anzahl & in \% (von1003) \\
\hline Blasenhalsenge & 14 & 1,4 \\
Harnröhrenstriktur & 12 & 1,2 \\
Bougierung & 2 & 0,2 \\
OP nach Sachse & 5 & 0,5 \\
OP nach Otis & 3 & 0,3 \\
Stent & 3 & 0,3 \\
Meatotomie & 1 & 0,1
\end{tabular}

Tabelle 38: Blasenhalsenge und Harnröhrenstriktur

\subsubsection{Inkontinenz}

Bei der Inkontinenz wurde zwischen Urge- und Stressinkontinenz unterschieden.

Dabei trat bei 16 Patienten eine Urgeinkontinenz auf (1,6\%), eine Stressinkontinenz (unterschiedlicher Auspägung) wurde von 9 Patienten angegeben $(0,9 \%)$.

\begin{tabular}{llll} 
& Anzahl & in \% (von 1003) \\
\hline Urgeinkontinenz & 16 & 1,6 \\
Stressinkontinenz I & 6 & 0,6 \\
Stessinkontinenz II & 2 & 0,2 \\
Stressinkontinenz III & 1 & 0,1 \\
gesamt & 25 & 2,5
\end{tabular}

Tabelle 39: Inkontinenz (postoperativ) 


\subsubsection{Impotenz}

Bei der Ermittlung der Impotenzrate wurde die Anzahl der Patienten mit Impotenz vor sowie nach der Operation erfasst.

Dabei gaben 37 Patienten (3,7\%) vor der Operation Probleme mit der Potenz an, bei 78 Patienten $(7,8 \%)$ kam es postoperativ zu einer erektilen Dysfunktion. Bei der Bestimmung der Fälle der Patienten, die vor und nach der Operation an Impotenz litten wurde eine Anzahl von 24 ermittelt. In 54 Fällen (5,4\%) war die Impotenz postoperativ neu aufgetreten.

\begin{tabular}{l|l|l|}
\hline Impotenz & Anzahl & in \% (von 1003) \\
\hline präoperativ & 37 & 3,7 \\
postoperativ & 78 & 7,8 \\
prä- und postoperativ & 24 & 2,4 \\
neu aufgetreten & 54 & 5,4
\end{tabular}

Tabelle 40: Impotenz

\subsection{Nachsorge}

Im Nachsorge-Kapitel wurden die Ergebnisse aus den Fragebögen sowie die Untersuchungsergebnisse der Nachsorge aus den Patientenakten analysiert.

Insgesamt wurden $153(15,1 \%)$ der 1011 Fragebögen ausgefüllt zurückgesandt, 37 Patienten wurden als verstorben gemeldet $(3,7 \%)$.

Erfasst wurden im folgenden die Miktionsfrequenzen, die Einstufung der Lebensqualität sowie weitere operative Eingriffe.

\subsubsection{Miktionsfrequenz (postoperativ)}

Bei der Ermittlung der postoperativen Miktionsfrequenz ergab sich tags ein Durchschnittswert von 4,2 (bei 187 auswertbaren Fällen), nachts lag die Miktionsfrequenz durchschnittlich bei 1,7 (200 Fälle).

\begin{tabular}{|l|l|l|}
\hline Miktionsfrequenz & tags & nachts \\
0 & 0 & 30 \\
1 & 0 & 67 \\
2 & 26 & 65 \\
3 & 62 & 23 \\
4 & 29 & 7 \\
5 & 31 & 4 \\
6 & 26 & 3 \\
7 & 3 & 1 \\
8 & 4 & 0 \\
$>8$ & 6 & 0 \\
Durchschnitt & 4,2 & 1,7
\end{tabular}

Tabelle 41: Miktionsfrequenz postoperativ 


\subsubsection{Lebensqualität (postoperativ)}

Bei der Einschätzung der Lebensqualität nach der Operation wurden 148 Fälle ausgewertet. Dabei lag der Durchschnitt bei 1,5 auf der Bewertungsskala von 0 bis 6.

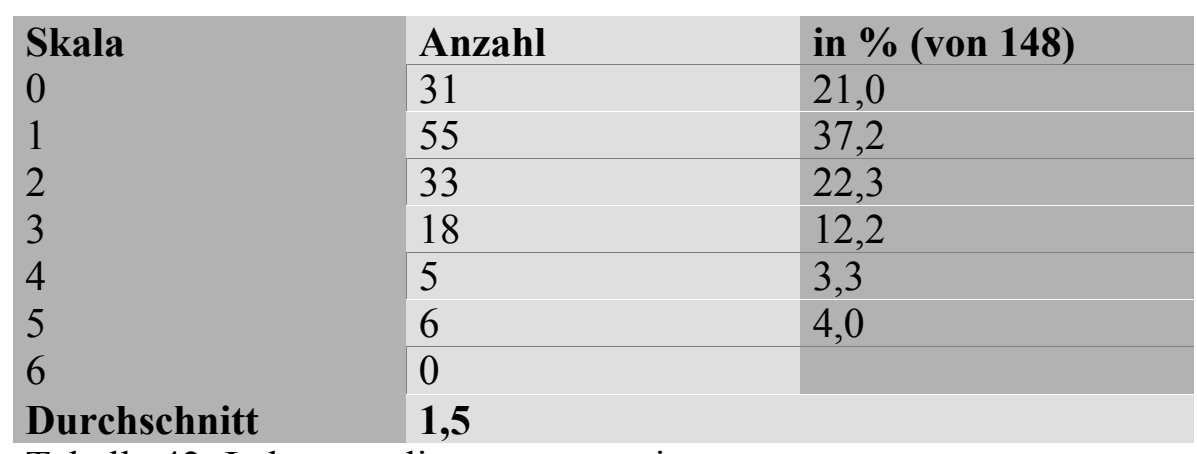

Tabelle 42: Lebensqualität postoperativ

\subsubsection{Folge-TURP}

Zuletzt wurden die Patienten befragt, ob weitere transurethrale Resektionen der Prostata stattgefunden hatten. Bei insgesamt 179 verwertbaren Fällen war bei 147 Patienten kein Folgeeingriff nötig (82,1\%). Bei 32 Patienten wurde eine weitere TURP durchgeführt, 29 $(16,2 \%)$ davon im Klinikum rechts der Isar (RDI), die restlichen 3 extern $(1,7 \%)$. Der Folgeeingriff im Klinikum rechts der Isar fand durchschnittlich nach 300,5 Tagen statt, 22 der Eingriffe wurden unter kurativem Ansatz durchgeführt, bei 7 Patienten war der Eingriff palliativ.

\begin{tabular}{l|ll|}
\hline $\begin{array}{l}\text { Folge-TURP } \\
\text { nein }\end{array}$ & Anzahl & in \% (von 179) \\
\hline ja, extern & 147 & 82,1 \\
ja, RDI & 3 & 1,7 \\
\hline
\end{tabular}

Tabelle 43: Folge-TURP 


\section{DISKUSSION}

\section{Ausgangssituation}

Um die Ergebnisse mit Früh- und Spätkomplikationen sowie die subjektive Zufriedenheit der Patienten mit der Operationsmethode TURP beurteilen zu können, ist die präoperative Ausgangssituation wichtig.

Bezüglich des allgemeinen Operationsrisikos wiesen 267 Patienten ein erhöhtes cardiales $(26,4 \%), 5(0,5 \%)$ ein deutliches pulmonales und $6(0,6 \%)$ ein signifikantes Thromboserisiko auf. 105 Patienten (10,4\%) standen unter Antikoagulation, bei 38 (3,8\%) lag ein behandlungsbedürftiger Diabetes mellitus vor.

Nach einer Erhebung von Tomamichel steigen verschiedene präoperative Risikofaktoren im Alter (über 80 -jährige Männer) auf $91,8 \%$ bei Herzkreislauferkrankungen, $49,3 \%$ bei pulmonalen Erkrankungen, 6,8\% bei Diabetes mellitus und 5,6\% bei Cerebralsklerose an (62).

Als urologische Vorerkrankungen bzw. Eingriffe wiesen 34 Patienten (3,4\%) eine Harnröhrenstriktur auf, bei $26(2,6 \%)$ trat in der Vorgeschichte eine Prostatitis, bei $28(2,8 \%)$ ein Blasentumor und bei $23(2,3 \%)$ eine Epididymitis auf. Bei 63 Patienten (6,2\%) lagen Blasensteine vor.

Als Voroperationen hatten bereits 59 Patienten $(5,8 \%)$ eine transurethrale Prostataresektion und $8(0,8 \%)$ eine Urethrotomie hinter sich. Bei der stat. Aufnahme waren 151 Patienten $(14,9 \%)$ mit einer suprabubischen Harnableitung, 120 Patienten (11,9\%) mit einem Dauerkatheter versorgt.

Die jetzt erfasste TURP war also bei 986 Patienten (97,5\%) bezüglich der Prostata ein Ersteingriff.

Fiedler nennt in einer Studie von über 507 Patienten eine Häufigkeit von 11,4\% mit Eingriffen im Bereich der Prostata vor TURP, so dass hier 88,6\% der TURP's als Erstoperationen zu nennen sind (21).

In der präoperativ durchgeführten Anamnese durch den Arzt war der Spitzenreiter bzgl. der Beschwerdesymptomatik die Nykturie mit 796 Patienten (78,7\%), gefolgt von Harnstrahlabschwächung mit 592 Patienten (58,6\%) sowie Harnverhalt mit 269 Patienten $(26,6 \%)$.

Über Restharn klagten 190 Patienten (18,8\%), über Startverzögerung 175 (17,3\%) sowie 167 über Nachtröpfeln (16,5\%). Eine Makrohämaturie gaben 76 Patienten an (7,5\%).

Bruskewitz et al. beschreiben eine ähnliche Zusammensetzung des Beschwerdebildes präoperativ, wobei die Betonung der Symptomatik stärker auf der Pollakisurie bzw. dem Nachtröpfeln liegt (17).

Die Diagnostik erfasste präoperativ allgemeine Laborausgangsbedingungen und den Nachweis bzw. Ausschluss eines Harnwegsinfektes sowie klinische und apparative Untersuchungsmöglichkeiten.

Präoperativ wurde bei 152 Patienten (15\%) ein signifikanter Harnwegsinfekt mittels Urikult festgestellt. 
In Hinsicht auf die Karzinomerkennung zeigten präoperativ 7,9\% (76 von 961 erfassten Fälle) einen suspekten rektalen Tastbefund. Bei 9 Patienten (von 187 erfassten) war durch eine Stanzbiopsie bereits präoperativ ein Prostatakarzinom histologisch gesichert. Aus der Gesamtheit der Vorbefunde wurde insgesamt bei 36 Patienten (3,6\%) präoperativ die Diagnose eines Prostatakarzinoms gestellt.

Der PSA-Wert lag dabei bei 774 Patienten unter $10 \mathrm{ng} / \mathrm{ml}(79,1 \%)$.

Vesey et al. berichten über einen geringen Anstieg des PSA-Wertes beim Karzinom und einen signifikanten Anstieg bei der benignen Prostatahyperplasie nach TURP, so dass dieser Wert postoperativ bei benigner Prostatahyperplasie nicht bestimmt werden sollte; ein Zusammenhang zwischen Gewicht der benignen Prostatahyperplasie und der Höhe des Laborwertes wird aufgezeigt (67).

Auch präoperativ erhöhte PSA-Werte sind bei benigner Prostatahyperplasie ohne Carcinomnachweis $\mathrm{zu}$ finden. Ursache sind die die BPH begleitenden entzündlichen Veränderungen oder Zirkulationsstörungen bei sehr grosser Prostata. Daneben sind medikamenteninduzierte PSA-Veränderungen möglich (31).

In einem vergleichbaren Patientengut von Chilton et al. mit 1004 Patienten betrug die Karzinomrate $12,3 \%$ (18).

Sheldon et al. zeigt in seinem Patientengut eine Zunahme der Häufigkeit des inzidentellen Prostatakarzinoms von $1,9 \%$ bei Patienten bis 39 Jahre auf $60 \%$ bei Patienten älter als 90 Jahre auf (57).

An der Spitze der Op-Indikationen (Mehrfachnennungen waren hierbei möglich) lag mit Abstand die subjektive Beschwerdesymptomatik (94,3\% mit obstruktiven und 16,8\% mit irritativen Miktionsbeschwerden), gefolgt von Harnverhalt mit 21,5\%, Restharn (>100ml) mit 8,3\%, Makrohämaturie mit 3,3\%, Hydronephrose mit 3,9\%, rezidivierenden Harnwegsinfekten mit $2,7 \%$ und Prostatitis mit $0,4 \%$.

Fiedler et al. nennt als OP-Indikation für eine TURP einen Restharn von mehr als $50 \mathrm{ml}$, Restharn von weniger als $50 \mathrm{ml}$ mit chronischem Harnwegsinfekt, Harnverhalt, Blutung und starke dysurische Beschwerden (21).

\section{Perioperativer Verlauf}

Die mittlere Operationszeit unter Einschluss der Begleitoperationen betrug bei 986 erfassten Patienten 69,7 Minuten bei einer Spannweite zwischen 10 und 210 Minuten.

In einer Studie aus Dänemark von Meyhoff ist eine mittlere Anästhesiezeit von 60 Minuten (20195 Minuten) bei 43 Patienten festgestellt worden (42). In einer Veröffentlichung nach Levin fand sich eine etwas kürzere OP-Zeit von 45,3 Minuten bei 392 Patienten, jedoch unter Ausschluss der Begleitoperationen (36).

Als Begleitoperationen wurde bei 242 Patienten (24\%) eine Blasenhalskerbung, bei 233 Patienten $(23,1 \%)$ eine Urethrotomia interna nach Otis und bei 53 Patienten $(5,2 \%)$ eine Urethrotomie nach Sachse durchgeführt. In 10 Fällen (1,0\%) war eine Meatotomie erforderlich, eine Circumcision wurde bei 6 Patienten $(0,6 \%)$ durchgeführt. Bei 14 Patienten wurde intraoperativ ein suprapubischer Blasenkatheter angelegt $(1,4 \%)$.

Bei 1660 Fällen von TURP's nach Hartung et al. war in 12,1\% vor Einführung eines 24 Charriere-Instrumentes eine Urethrotomia interna notwendig; die Nachuntersuchung ergab dabei eine postoperative Strikturquote von 5,1\% ohne und 2,6\% mit Urethrotomia interna (26). 
Fiedler et al. nennt als Begleitoperationen in erster Linie die Blasensteinentfernung mit 7,7\% (39 von 507), Urethrotomia interna mit 2,2\% (11 von 507), Meatotomie mit 1,2\% (6 von 507), Spermatocelenabtragung mit $0,6 \%$ (3 von 507), Circumcision mit $0,4 \%$ (2 von 507) und Hydrocelenabtragung mit $0,2 \%$ (1 von 507) (21).

Das mittlere Resektionsgewicht lag bei 994 Patienten bei 35,4 Gramm, das minimale bzw. maximale Resektionsgewicht betrug 1 bzw. 120 Gramm.

Dies liegt etwas höher als die Angaben in der Literatur z.B. bei Levin mit 28 Gramm bei 392 Patienten (36). Andere Autoren (Sikafi et al.) berichten über ein deutlich niedrigeres mittleres Resektionsgewicht von 10,2 Gramm (Spanne zwischen 2 und 50 Gramm) (58). Malone et al. nennen ein mittleres Resektionsgewicht von 20,4 Gramm bei einer Breite zwischen 1 und 85 Gramm (39).

Bei der Analyse des Patientengutes ergab die histologische Aufarbeitung insgesamt bei 99,4\% (942 von 948 Fällen) eine benigne Prostatahyperplasie, 36,5\% (346 Patienten) wiesen eine Prostatitis auf, während in 5,5\% (52 Fälle) die Diagnose eines Prostatakarzinoms gestellt wurde. Fiedler et al. erhielt in einer deutschen Studie eine ähnliche Rate von 4,9\% (25 von 507) Prostatakarzinom (21), (46).

Die durchschnittliche Katheterverweildauer lag bei 2,2 Tagen, die Spanne reichte von 1 Tag bis zu 35 Tagen.

Der postoperative Verbleib des Dauerkatheters betrug dagegen bei Meyhoff et al. 4 Tage (2 bis 16 Tage) (43).

Eine Blutsubstitution war bei insgesamt 137 Patienten (13,7\%) nötig. Dabei war bei 9,8\% (98 von 997 erfassten Fällen) des Patientengutes eine intraoperative Substitution nötig, 5,0\% der Patienten (50 von 986) wurden postoperativ transfundiert.

In einer Erhebung von Singh et al. bei 935 Fällen in England waren in 8,9\% Bluttransfusionen nötig (59). Deutlich höher war die Rate in einer Studie nach Meyhoff et al. mit einer Blutsubstitution von 33\% der Patienten (43).

\section{Intraoperative Komplikationen}

Bei 1,9\% (19 von 998) der Patienten kam es intraoperativ zur Sinuseröffnung, bei 1,4\% (14 Patienten) zur Prostatakapselperforation und bei $0,4 \% \quad(4$ von 998$)$ zu einer Blasenhalsperforation.

Deren Häufigkeit wird im Schrifttum mit 1,5 bis 5\% unter Verzicht auf eine Zystographie nach TURP angegeben, larvierte Perforationen bleiben dabei meist unbemerkt. Je nach Ausmass der Radikalität ist die Perforation der sogenannten chirurgischen Kapsel möglich, so dass nach systematischer postoperativer Zystographie bei palliativer Adenomresektion bzw. infolge Prostatakarzinom eine Häufigkeit von $8,2 \%$ bzw. 8,0\%, nach radikaler Adenektomie von 20\% besteht (33).

In einem grossen Patientenkollektiv aus England nach Singh bewegte sich die Rate der Perforationen bei $0,5 \%$ (5 von 935 TURP's) (59).

Dies entspricht in etwa der Beobachtung von Chilton mit $0,4 \%$ Perforationshäufigkeit (4 von 1004) (18). Auch Fiedler beschreibt eine Rate von 0,39\% (2 von 507 Patienten) (21). Lundus nennt einen Häufigkeit von 1,2\% (1 von 83) bei kompletter Resektion (37). 
In $0,7 \%$ (7 von 998) kam es zu einer Unterfahrung; eine Schleimhautabhebung bemerkte Fiedler in $0,39 \%$ (2 von 507 Patienten) (21).

Ein TUR-Syndrom trat bei 3 Patienten auf $(0,3 \%)$.

\section{Allgemeine Komplikationen}

Als operationsunspezifische Komplikationen traten Pneumonien in $0,6 \%$, Lungenembolie mit $0,1 \%$, dekompensierte Herzinsuffizienz mit $0,2 \%$ und Apoplex mit $0,1 \%$ auf.

Kein Patient verstarb während des stationären Aufenthaltes nach TURP im Gegensatz zu den Angaben in der Literatur nach Singh mit einer Mortalität von 1,28\% bei 935 TURP's innerhalb von 4 Wochen (59). In einer Veröffentlichung von Ball mit einem Durchschnittsalter von 70,3 Jahren ligt die Mortalitätsrate bei $1,16 \%$, bei elektiven Eingriffen bei $0,92 \%$ (6). Chilton beschreibt eine Mortalitätsrate von 1,0\% bei 1004 Patienten (18). Eine Operationsletalität von 1,38\% mit Lungenembolie, Lungenödem und und Herzinsuffizienz mit jeweils 2 Patienten, einmal Bronchopneumonie als Ursache war bei 7 von 507 Fällen nach TURP nach Angaben von Fiedler zu erfassen (21).

Im Gegensatz dazu liegt die Mortalitätsrate bei insgesammt 1444 Patienten bei einer Veröffentlichung von Brandhauer aus dem Jahre 1969 noch bei 3,3\% (14).

\section{Frühkomplikationen}

$\mathrm{Zu}$ Nachblutungen kam es bei insgesamt 42 Patienten (4,2\%), eine Nachkoagulation war bei 22 Patienten nötig (2,2\%). Auch in der Literatur wird die Häufigkeit der Nachkoagulation nach Chilton mit 2,1\% (21 von 1004) beschrieben (18). Etwas niedriger liegt die Rate bei Fiedler mit $1,6 \%$ (8 von 507 Patienten) (21).

Postoperativ wiesen 73 Patienten (7,3\%) einen Harnverhalt auf, welcher in 46 Fällen die Einlage eines Dauerkatheters, bei 27 Patienten eine suprapubische Harnableitung nötig machte.

Eine Nachresektion während des stationären Aufenthaltes wurde bei 51 Patienten durchgeführt $(5,1 \%)$.

In einer Untersuchung von Tomamichel et al. bei über 80-Jährigen Patienten war bei 7\% (11 von 160 Patienten) eine Nachresektion indiziert (62). Fiedler et al. beschreibt innerhalb von 30 Tagen nach TURP eine Häufigkeit von 6,7\% an Nachresektionen (21).

$\mathrm{Zu}$ einem postoperativ nachgewiesenen Harnwegsinfekt kam es bei 38 Patienten $(3,8 \%)$, bei 2 Patienten trat eine Nebenhodenentzündung auf, während eine Urethritis nicht beobachtet wurde.

Frühkomplikationen waren bei über 80 -jährigen Patienten nach Tomamichel in 1,3\% (2 von 160) eine Nachblutung und in je $0,6 \%$

(1 von 160) ein TUR-Syndrom, ein Ulcus duodeni, eine Pneumonie und eine Urosepsis; die Operationsletalität betrug 1,3\% (Bronchopneumonie bzw. GIT-Blutung) (62).

Als Komplikationen bei insgesamt 43 Patienten wird bei Meyhoff ein Harnwegsinfekt unmittelbar nach TURP in 30\%, nach Demissio in 22\%, eine Epididymitis in $7 \%$, pulmonale bzw. kardiale Komplikationen in $2 \%$ bzw. $7 \%$ beschrieben (43). 


\section{Spätkomplikationen}

An Spätkomplikationen wurden Blutung, Blasenhalsenge, Harnröhrenstriktur und Inkontinenz erfasst.

Bei 2,1\% aller Patienten kam es zu einer spät einsetzenden Blutung, die Revision erfolgt überwiegend über einen Spülkatheter, eine Koagulation oder zystoskopische Hämatomausräumung waren eher selten nötig.

Eine Harnröhrenstriktur trat bei 12 Patienten (1,2\%) auf, wobei die Diagnose nach durchschnittlich 581,4 Tagen gestellt wurde. Therapeutisch kamen Bougierungen (2), Urethrotomia interna nach Sachse (5) und Otis (3), Stenteinlage (3) sowie eine Meatotomie zur Anwendung.

In einem vergleichbaren Patientengut von Singh lag die Rate der Harnröhrenstrikturen bei 3,75\% transient und bei 0,5\% permanent (59).

Bisher wurden als Ursache z.B. bei offenem Resektionsverfahren für Strikturen diskutiert: Immunschwächen, resultierende Infektionsgefahr und fehlender Harnfluss mit terminalem Nierenversagen.

Dicht unterhalb des Epithels der Harnröhre liegt das Stratum proprium, eine sehr dünne, gefässreiche Gewebeschicht mit wenigen elastischen Fasern. Mit dem Einbringen des Resektoskopes kommt es dabei fast zwangsläufig bei einem grossen Durchmesser zu einer Verletzung des Epithels mit der Möglichkeit des Eindringens von Urin oder infiziertem Material, so dass aus relativ geringfügigen Verletzungen deutliche Narbenbildungen und Strikturen entstehen können.

Strikturursachen dürften dabei nach Hartung präoperativ traumatische Bougierung, Katheterisierung oder Urethrozystoskopie, intraoperativ ein Missverhältniss von Urethrallumen und Instrumentkaliber, rasche Bougierung, scharfkantige oder rauhe Geräte, ungenügend Gleitmittel, Leckströme oder fehlerhafte Isolierung, postoperativ die Dauer der Katheterbehandlung, Katheterpflege vor allem im Bereich des Meatus externus urethrae und die Katheteroberfläche sein (26).

Für die Entstehung einer Harnröhrenstriktur wird nach Madersbacher ebenfalls das Ausmass der Harnröhrenläsion durch die Instrumentation und die postoperative Urethritis verantwortlich gemacht (38).

Das Auftreten von Strikturen nach TURP ist in den besonderen morphologischen Verhältnissen der männlichen Harnröhre sowie deren hohen Vulnerabilität bei mechanischen Schädigungen bei Missverhältnis zwischen Instrumentendurchmesser und Harnröhrenlumen zu sehen, so dass nach Sachse eine Bougierungsbehandlung (Gewebezerreissung) oder besser Urethrotomie interna (scharfer Schnitt) durchgeführt und anschliessend für 2 bis 3 Tage Terracortrilgel in den geschlitzten Meatus gebracht werden sollte; Komplikationen bei der Katheterisierung im Bereich der Meatusstenose und von Harnröhrenstrikturen sind $\mathrm{zu}$ vermeiden, perioperativ sollte eine hochpotente antibiotische Prophylaxe durchgeführt werden (54).

Intraoperativ steht nach Sachse die Vermeidung von Leckströmen zwischen Resektionsschaft und Harnröhrenwand und Auswahl des optimalen Gleitmittels (elektrisch gut leitend) im Vordergrund (54).

Harnröhrenstrikturen nach TURP werden in einer amerikanischen Studie von Lentz bei 2223 Resektionen beinflusst durch: eine initiale Erfassung des Durchmessers der Urethra vor Einführung des Instrumentes, gegebenenfalls gefühlvolle Urethradilatation, Anwendung einer perinealen Urethrostomie bei Strikturen der Harnröhre und Wahl der richtigen Grösse der urethralen Katheter postoperativ; bei einer präoperativ bereits bestehenden Striktur die mit einer perinealen Urethrostomie behandelt wurde, besteht eine Strikturrate von 8,45\%, bei einer 
normalen TURP von 19\% zusätzlichen Strikturen postoperativ; ohne präoperativ vorhandene Striktur eine Strikturrate von 6,3\% postoperativ (35).

Bruskewitz nennt bei seinem Patientengut eine Harnröhrenstrikturrate von 5\%, während es in $10 \% \mathrm{zu}$ einer Blasenhalskontraktur kommt (17).

Zur DK-Einlage werden nach Sachse Produkte mit glatter Oberfläche (Silikonkatheter), die Applikation eines Gleitmittels mit darin enthaltenem Desinfektionsmittel zur Prophylaxe einer Urethritis mit Absonderung eines Sekrets als Nährboden für Bakterien, die Verhinderung der Keimaszension durch Silber- oder Kupferionen in der Katheterwand und sterile Katheter mit geschlossenem Harnableitungssystem empfohlen (54), (61).

Vom Material des Katheters her werden von Blacklock dabei nicht-toxische PolyvinylchloridKatheter und Silikon-Katheter empfohlen (12).

Die Dauer der Resektionszeit ist nach Lentz ohne Beeinflussung auf die Strikturhäufigkeit; sie wird verursacht durch Verletzung der Schleimhaut (vorher Durchmesser bestimmen, gegebenenfalls dilatieren, Gleitmittel verwenden) und Harnwegsinfekte, welche vorher therapiert werden sollten, um Entzündungen des verletzten Epithels zu vermeiden (35).

Die totale Inzidenz von Harnröhrenstrikturen bei Lundus nach im Schnitt 3,5 Jahren war bei 8,5\% ohne Abhängigkeit vom Ausmass der Resektion, wobei präoperativ instrumentelle Eingriffe im Bereich der Urethra ein erhöhtes Risiko darstellen dürften (8 von 34, d.h. 24\%) (37).

Durch regelmässige Blasenfüllung wird die Aufrechterhaltung des Harnflusses mit ständiger Reinigung des Wundgebietes und hydraulischer Bougierung der Harnröhre erreicht; ein vermehrtes Flüssigkeitsangebot über die Harnblase sollte nach Britten bis zur Stabilisierung der Wundheilung fortgeführt werden, gegebenenfalls auch durch eine suprapubische Fistel (15).

Die Lokalisation der Urethrotomia interna postoperativ liegt nach Hartung im Bereich der pysiologischen Engstellen: Meatus externus (56,9\%), Fossa navicularis (26,2\%), Pars pendulans $(7,2 \%)$ und Blasenhals $(9,7 \%)$ (26).

Tomamichel berichtet in einer Studie bei über 80-jährigen Patienten von einer Gesamtstrikturrate von 6,3\% (10 von 158), wobei je 1,9\% im Bereich des Meatus und des Blasenhalses auftraten, $2,5 \%$ in der Urethra (62).

Bailey und Shearer berichten über eine Strikturrate nach TURP von $0 \%$ mit und 10\% (9 von 90 Patienten) ohne Otis-Urethrotomie (5).

Eine Blasenhalsenge wurde postoperativ bei 14 Patienten $(1,4 \%)$ festgestellt, der durchschnittliche Zeitraum zwischen Operation und Diagnosestellung betrug 612 Tage.

Blasenhalskontrakturen treten in der Literatur in etwa 2,16\% bzw. 2,23\% vor allem bei kleinen Primäradenomen bzw. rezidivierender transurethraler Therapie ohne höhere Häufigkeit als bei transvesikaler Adenomektomie auf; als ursächlich werden von Matz Läsionen der chirurgischen Kapsel oder des Trigonums, persistierende Harnwegsinfekte und entzündlich vorgeschädigte Adenome diskutiert (40).

Die Blasenhalskontraktur ist nach Meinung von Lundhus in erster Linie bedingt durch das Trauma am Blasenhals während der Resektion, wobei eine fibrosierte oder Steine enthaltende Prostata oder Prostatitis ein erhötes Risiko darstellen dürften (37).

In einer Veröffentlichung einer Studie bei einem grossen Patientengut durch Sikafi liegt die Blasenhalskontrakturinzidenz bei $0,86 \%$, prophylaktisch wird die Vermeidung einer radikalen Resektion bei kleinen Prostatae angeraten (58).

Die Inkontinenzrate betrug postoperativ insgesamt 2,5\% (25 von 1003 Patienten), wobei 1,6\% eine Urgeinkontinenz angaben und bei $0,9 \%$ eine Stressinkontinenz vorlag.

Ein Monat postoperativ lag die Inkontinenzrate nach Tomamichel bei über 80-jährigen Patienten nach TURP 3,8\% (6 von 158) (62). 
Er beschreibt nach TURP typische Inkontinenzformen: zum einen die Überlaufinkontinenz mit erhöhtem Restharnvolumen und Harnabgang ohne das Gefühl des Harndranges, zum anderen die Dranginkontinenz mit gesteigertem, imperativen Harndrang und nicht hemmbarer Detrusormotorik, so dass bei intraabdomineller Drucksteigerung unwillkürlich Harn verloren wird; die Urge-Inkontinenz mit Detrusorhyperreflexie und deutlich erhöhtem intravesikalem Druck tritt vor allem bei Läsionen der cerebralen Kontrollfunktion bzw. des urethralen Sphinkters nach TURP auf (62).

Als Ursache konnte bei Reid in 74\% eine Läsion des externen Sphinkters gefunden werden, therapeutisch am erfolgreichsten in der Behandlung von Patienten mit Urininkontinenz nach Prostatektomie war die prothetische Versorgung (65\% Erfolgsrate), gefolgt von konservativer medikamentöser Therapie, während die endoskopische Revision mit einem unbefriedigenden Effekt einherging (50).

Nach Obrant kam es nach TURP innerhalb von 4 Monaten bei vielen Patienten zu einer transienten, bei lediglich 4 von 186 Patienten $(2,2 \%)$ zu einer persistierenden Inkontinenz, wobei dies zumindest zu einem Teil mit einer cerebralen Läsion verbunden war (47).

Fowler berichtet innerhalb von 12 Monaten nach TURP bei BPH-Patienten von einer Rate von $4 \%$ von Patienten mit neu aufgetretener Inkontinenz, während die Häufigkeit der transienten Inkontinenz deutlich höher lag (22).

Über eine neu aufgetretene Impotenz nach der TURP berichteten 5,4\% (54 von 1003), wobei sich eine gesamte Impotenzrate von 7,8\% (78 von 1003) ergab, wovon jedoch bei $2,4 \%$ (24 von 1003 ) bereits präoperativ eine erektile Dysfunktion bestand.

Zwischen 1976 und 1989 haben sich insgesamt 11 Arbeitsgruppen mit dieser Symptomatik in Fragebögen, Interviews und NPT-Messung (nächtliche penile Tumeszenzmessung) beschäftigt, 0 bis $40 \%$ der untersuchten Patienten waren nach TURP oder Adenektomie impotent, wobei die über 60-Jährigen nach Keuler jedoch nur zu 64\% sexuell aktiv sind (32).

Fowler et al. berichten über eine Impotenzrate von 5\% bei BPH-Patienten nach TURP bei präoperativ sexuell aktiven Männern (22).

Lundhus findet keine Korrelation zwischen der Radikalität der TURP und einer möglichen sexuellen Dysfunktion (37).

Eine thermische Schädigung nach TURP des für die Sexualfunktion nötigen Nervengewebes scheint aufgrund gleichen Erektionsvermögens nach unterschiedlichen Prostatektomieverfahren für Keuler unwahrscheinlich zu sein; da die vita sexualis in verschiedenen Altersgruppen sich verändert und zudem von unterschiedlichen weiteren Faktoren abhängig ist, dürften weitere Untersuchungen mit altersgruppenbezogenen Differenzierungen und genauen Analysen des präoperativen Status notwendig sein (32).

\section{Nachsorge}

Von den Patientenfragebögen wurden 15,1\% (153 von 1011) ausgefüllt zurückgesandt, 3,7\% der Patienten (37 von 1011) wurden als verstorben gemeldet.

Bei der Frage nach der postoperativen Miktionsfrequenz wurde ein durchschnittlicher Wert von 4,2 tagsüber und 1,7 nachts angegeben.

Im Vergleich mit den präoperativen Ausgangswerten (durchschnittliche Miktionsfrequenz tagsüber von 6,7 und nachts von 3,4) kam es hier $\mathrm{zu}$ einer eindeutigen Besserung der Beschwerden.

Die Lebensqualität wurde von den Patienten prä- sowie postoperativ auf einer Skala von 0 bis 6 selbst eingestuft. Der durchschnittliche Wert bzgl. der subjektiven Lebensqualität lag präoperativ bei 3,7 ,

postoperativ zeigte sich eine deutliche Besserung auf einen Durchschnittswert von 1,5. 
Befriedigende subjektive Ergebnisse bei 90\% nach TURP mit bleibender Verbesserung der obstruktiven und irritativen Beschwerden zeigt eine dänische Studie von Meyhoff, wobei die Nykturie als vorherrschendes Symptom bei mehr als 50\% nach 5 Jahren dominiert (44).

93\% der Patienten mit ernsthaften und 79\% der Patienten mit mässigen Beschwerden stellten in einer Veröffentlichung nach Fowler eine Verbesserung der Symptome fest (22).

Abrams beschreibt in $88 \%$ seiner Patienten eine Verbesserung der Beschwerdesymptomatik, in $12 \%$ keine Veränderung, während in keinem Fall eine Verschlechterung auftritt (1).

Nach Bruskewitz schätzen nach einem Jahr 84\%, nach 3 Jahren nach TURP $75 \%$ der Patienten ihre Beschwerdesymptomatik als verbessert im Vergleich zum Ausgangsstatus ein (17).

Eine Studie von Singh et al. mit insgesamt 935 Fällen zeigte eine Verbesserung bei 97,3\%, keine Veränderung durch den Eingriff bei 1,6\% und eine Verschlechterung bei 1,1\% der Patienten (59).

Nach einer Studie von O'Sullivan et al. zeigte sich eine deutliche Verbesserung der Lebensqualität 3 Monate nach TURP (49).

Bei 147 von 179 auswertbaren Fällen war im Untersuchungszeitraum keine weitere TURP nötig. Bei 32 Patienten (17,8\% bzw. 3,2\% bei 179 bzw. 1011 Patienten) wurde eine weitere TURP durchgeführt, 29 davon im Klinikum rechts der Isar, die restlichen drei extern. Der Folgeeingriff fand nach durchschnittlich 300,5 Tagen statt.

In einem grossen Patientengut aus Dänemark, England und Kanada von Roos betrug die Häufigkeit der Zweitresektionen nach TURP zwischen 12 und 15,5\% (52), nach Varkarakis bei $6 \%(66)$.

Deutlich geringer liegt der Prozentsatz bei Bruskewitz mit einer Rate von 2\% an erneuten TURP's (17).

Die Inzidenz der Reoperation nach TURP hängt nach Lundhus nicht von der Radikalität der Resektion ab (37).

In einer Veröffentlichung von Meissner über transurethrale Zweiteingriffe am Blasenhals unter anderem nach TURP finden sich 3,4\% (44 von 1300) TURP's wegen einens Restadenoms und $0,2 \%$ (3 von 1300) wegen eines Rezidivs (41).

Die Revisionsrate mittels TURP in einer anderen Erhebung durch Singh betrug 6,0\% (56 von 935 Patienten) (59).

Meyhoff beschreibt in einer Langzeitstudie innerhalb von 5 Jahren nach TURP bei 43 Patienten 3 Nachkoagulationen (7\%), 7 Strikturen (16\%), 5 erneute TURP's (12\%), 2 Lithotrypsien (5\%) und eine Epidymektomie (2\%) (44).

Zusammenfassend stellt die TURP am Klinikum rechts der Isar in München für die benigne Prostatahyperplasie ein wenig belastendes Therapieverfahren mit sehr guten subjektiven Ergebnissen bezüglich der Beschwerden beim Wasserlassen bzw. der Lebensqualität bei niedrigen Komplikationsraten und relativ kurzer postoperativer Aufenthaltsdauer dar.

Nach den Ergebnissen der vorliegenden Erhebung dürfte die TURP bei benigner Prostatahyperplasie weiterhin den Goldstandard darstellen, an dem sich neu entwickelte Therapieverfahren vor allem in Hinsicht auf Langzeitergebnisse zu messen haben. Lediglich für kleine Prostatae mit fibromuskulärer Hyperplasie stellt die Blasenhalsinzision bzw. ein medikamentöser Therapieversuch eine Alternative dar, bei sehr grossen Prostatae ist eine offenes Resektionsverfahren zu wählen 


\section{ZUSAMMENFASSUNG}

Nachdem in den letzten Jahren verschiedene Alternativverfahren zur Behandlung des benignen Prostata Syndroms entwickelt wurden, muss die „Goldstandardtherapie“ TURP neu evaluiert werden. In einer retrospektiven Studie wurden von Januar 1989 bis Dezember 1997 alle durchgeführten TURP's untersucht; dabei waren insgesamt 1011 Fälle auswertbar.

\section{Präoperative Diagnostik}

Bei 95,1\% der Patienten wurde bei Aufnahme eine digital-rektale Untersuchung durchgeführt, davon erschienen 7,9\% suspekt.

Bei der Bestimmung des prostataspezifischen Antigens (PSA) lag der Durchschnittswert bei 5,8 ng/ml (ohne den Fällen mit postoperativ gesichertem Karzinom).

Bei der Bestimmung des Prostatagewichtes präoperativ lag der durchschnittliche Wert bei 67 Gramm, das Adenomgewicht wurde mit einem Mittelwert von 40,9 Gramm bestimmt.

Bei 181 durchgeführten Stanzbiopsien lautete das histologische Ergebniss in 96,8\% benigne Prostatahyperplasie, in 4,8\% Prostatakarzinom, in 4,3\% PIN und in 52,4\% chronische Prostatitis.

\section{Perioperativer Verlauf}

Die durchschnittliche Operationszeit lag bei 69,7 Minuten (10 - 210 Minuten).

Das durchschnittliche Resektionsgewicht lag bei 35,4 Gramm.

Histologisch ergab sich in 99,4\% eine benigne Prostatahyperplasie , 36,5\% Prostatitis, 5,5\% Karzinom und 2,2\% PIN (Mehrfachnennungen).

Die mittlere Liegezeit des Dauerkatheters betrug 2,2 Tage (1-35 Tage).

Insgesamt war bei $13,7 \%$ der Patienten eine Bluttransfusion nötig.

\section{Frühkomplikationen}

Bei insgesamt 1003 erfassten Fällen kam es bei 15,1\% zu Frühkomplikationen.

$\mathrm{Zu}$ Nachblutungen kam es bei 4,2\% der Patienten.

Ein erhöhter Restharn wurde bei 2,9\% des Patientengutes nachgewiesen, zu einem Harnverhalt kam es in 7,3\%, wobei bei 2,7\% eine suprapubische Harnableitung nötig war.

Eine Nachresektion während des stationären Aufenthaltes war in 5,1\% der Fälle nötig.

Ein signifikanter Harnwegsinfekt wurde postoperativ bei 3,8\% nachgewiesen, eine Epididymitis in $0,2 \%$.

\section{Spätkomplikationen}

Eine Blasenhalsenge trat nach durchschnittlich 612 Tagen bei 1,4\% des Patientengutes auf, zu einer Harnröhrenstriktur war es bei 1,2\% gekommen (im Mittel nach 581,4 Tagen).

Über Inkontinenzbeschwerden klagten postoperativ 2,5\% der Patienten.

7,8\% der Patienten gaben postoperativ eine Impotenz an, somit ergibt sich nach Abzug derer, die bereits präoperativ an einer erektilen Dysfunktion gelitten hatten, eine Rate von 5,4\% an neu aufgetretenen Fällen. 


\section{Nachsorge}

Bei der Ermittlung der postoperativen Miktionsfrequenz ergab sich ein Durchschnittswert von tagsüber 4,2 (präoperativ 6,7) und nachts 1,7 (präoperativ 3,4).

Ihre Lebensqualität postoperativ beurteilten die Patienten durchschnittlich mit 1,5 auf der Skala zwischen 0 und 6 (präoperativ 3,7).

Bei 17,9\% der Patienten war im weiteren Verlauf eine Folge-TURP nötig, wobei die Histologie (benigne Prostatahyperplasie oder Karzinom) hierbei nicht berücksichtigt wurde.

Aufgrund der Ergebnisse dürfte die TURP weiterhin den Goldstandard bei der Behandlung der benignen Prostatahyperplasie darstellen. 


\section{ANHANG}

\subsection{Fragebogen}

Name: $\quad$ Vorname: Geb. Datum

1) Hat sich an Ihren Beschwerden nach der bei uns durchgeführten Prostataoperation etwas verändert?

Beschwerden sind deutlich besser $\mathrm{O}$

Beschwerden haben sich leicht verbessert

Beschwerden sind unverändert

$\mathrm{O}$

Es ist eine Verschlechterung eingetreten

$\mathrm{O}$

2) Der Harnstrahl war/ist
vor der
nach der
Prostataoperation
Prostataoperation

kräftig

$\mathrm{O}$

$\mathrm{O}$

leicht abgeschwächt

$\mathrm{O}$

$\mathrm{O}$

stark abgeschwächt

$\mathrm{O}$

$\mathrm{O}$

es war kein spontanes

Wasserlassen möglich $\mathrm{O}$

$\mathrm{O}$

3) Wie oft mußten Sie vor der Prostataoperation Wasserlassen ?

$\begin{array}{lll} & \text { tags: } & \text { nachts: } \\ 0 \times & \mathrm{O} & \mathrm{O} \\ 1-2 \mathrm{x} & \mathrm{O} & \mathrm{O} \\ 3-4 \mathrm{x} & \mathrm{O} & \mathrm{O} \\ >4 \mathrm{x} & \mathrm{O} & \mathrm{O}\end{array}$

4) Wie groß war Ihr Restharn nach der Operation (falls vom Urologen bzw. Hausarzt gemessen)? $\mathrm{ml}$ 
Wie oft pro Tag müssen Sie nach der Prostataoperation Wasserlassen ?

$\begin{array}{lll} & \text { tags: } & \text { nachts: } \\ 0 \times & \mathrm{O} & \mathrm{O} \\ 1-2 \mathrm{x} & \mathrm{O} & \mathrm{O} \\ 3-4 \mathrm{x} & \mathrm{O} & \mathrm{O} \\ >4 \mathrm{x} & \mathrm{O} & \mathrm{O}\end{array}$

5) Unterzogen Sie sich in der Folge noch weiteren Operationen an der Prostata?

$$
\text { ja } \mathrm{O} \text { nein } \mathrm{O}
$$

Wenn ja, welche Art von Operation:
a) erneute Ausschälung der Prostata
$\mathrm{O}$
b) Prostataoperation mittes Bauchschnitt
$\mathrm{O}$
c) Wärmetherapie der Prostata
$\mathrm{O}$
d) Lasertherapie der Prostata
$\mathrm{O}$
e) Dehnung der Harnröhre (Bougierung)
$\mathrm{O}$
f) Schlitzung der Harnröhre
$\mathrm{O}$
g) andere Operation:
$\mathrm{O}$

6) Waren Sie bezüglich Ihrer Potenz vor der Prostataoperation bzw. nachher beeinträchtigt ?

$$
\text { vor der Operation nach der Operation }
$$

$\begin{array}{lll}\text { volle Gliedsteife } & \mathrm{O} & \mathrm{O} \\ \text { halbe Gliedsteife } & \mathrm{O} & \mathrm{O} \\ \text { keine Gliedsteife } & \mathrm{O} & \mathrm{O}\end{array}$

7) Waren Sie in Ihrer Ejakulationsfähigkeit (Samenerguß) vor bzw. nach der Prostataoperation beeinträchtigt?

$$
\text { vor der Operation nach der Operation }
$$

$\begin{array}{lll}\text { ja } & \mathrm{O} & \mathrm{O} \\ \text { nein } & \mathrm{O} & \mathrm{O}\end{array}$

8) Verloren bzw. verlieren Sie unfreiwillig Urin?

$\begin{array}{lll} & \text { vor der Operation } & \text { nach der Operation } \\ \text { ja } & \mathrm{O} & \mathrm{O} \\ \text { nein } & \mathrm{O} & \mathrm{O}\end{array}$


Falls es nach der Prostataoperation zu unfreiwilligem Urinverlust kam, wieviele Vorlagen benötigen Sie ?

tags : ..... Stück nachts: ..... Stück Markenname:

Urinabgang findet statt: beim Husten, Niessen, Heben, Laufen $\quad$ O bei plötzlich auftretendem Harndrang $\quad \mathrm{O}$ dauernd $\quad \mathrm{O}$

9) Wie schätzen Sie die Verbesserung Ihrer Lebenssituation durch die Prostataoperation bei uns ein, bzw. wie hätten Sie die Situation vor der Prostataoperation klassifiziert ?

$\begin{array}{llllllll}\text { vor Prostataoperation } & 0 & 1 & 2 & 3 & 4 & 5 & 6\end{array}$

nach Prostataoperation $\quad \begin{array}{lllllll}0 & 1 & 2 & 3 & 4 & 5 & 6\end{array}$

0=ausgezeichnet, 1=zufrieden, 2=überwiegend zufrieden, 3=gemischt, teils zufrieden, teils unzufrieden,

4=überwiegend unzufrieden, 5=unglücklich, $6=$ sehr schlecht

10) Geben Sie bitte an, den Namen Ihres

Urologen:

Hausarztes:

Verehrter Patient, wir dürfen uns für Ihre Mithilfe sehr herzlich bedanken. Sie helfen damit nicht nur uns, sondern letztlich den Patienten, die an derselben Erkrankung leiden.

Damit Ihnen keine zusätzlichen Kosten entstehen, liegt ein bereits frankierter Umschlag bei. 


\subsection{Tabellen und Abbildungen}

Tabellen- Titel:

Nummer:

1 Ätiologieansätze der benignen Prostatahyperplasie

$2 \quad$ Flußdiagramm der benignen Prostatahyperplasie

3 Übersicht über antiandrogene und androgenablative Substanzen

4 Beispiele von $\alpha$-Blockern unterschiedlicher Selektivität

5 Beispiele von Phytotherapeutika bei der Behandlung der benignen

Prostatahyperplasie

$6 \quad$ Vorteile der verschiedenen Zugangswege (offene Operation)

$7 \quad$ Vor- und Begleiterkrankungen

$8 \quad$ Urologische Vorerkrankungen

9 Urologische Voroperationen/Eingriffe

$10 \quad$ Symptomatik

11 Miktionsfrequenz (präoperativ)

12 Lebensqualität (präoperativ)

13 Digital-rektale Untersuchung

$14 \quad$ Kreatinin

15 Prostata Spezifisches Antigen

16 Sonographie der Nieren

17 Restharn

18 Transrektaler Ultraschall (Gesamtgewicht)

19 Transrektaler Ultraschall (Adenomgewicht)

20 Histologie/Diagnostik

21 Ausscheidungsurogramm

$22 \quad$ Zystoskopie

23 Indikation

24 Präoperative Diagnose

25 Anästhesieverfahren

$26 \quad$ Spülflüssigkeit

27 Zusatzeingriffe

28 Resektionsgewicht

29 Histologischer Befund

30 Dauerkatheter (Verweildauer)

31 Hämoglobinwert

32 Transfusionen

$33 \quad$ Natrium-Werte

$34 \quad$ Intraoperative Komplikationen

35 Allgemeine Komplikationen

$36 \quad$ Revision bei Nachblutung

$37 \quad$ Entzündungen postoperativ

38 Blasenhalsenge und Harnröhrenstriktur

39 Inkontinenz postoperativ

$40 \quad$ Impotenz

$41 \quad$ Miktionsfrequenz postoperativ

$42 \quad$ Lebensqualität postoperativ

43 Folge-TURP 
Abbildung- Titel:

Nummer:

1

Anatomie der Prostata nach Mc Neal

Androgenstoffwechsel in der menschlichen Prostatazelle 


\subsection{Literaturverzeichnis}

Nummer: Literatur:

1 Abrams, P. H., Farrar, D. J., Turner-Warwick, R. T.,Whiteside, C. G., Feneley, R. C. L.: The Results of Prostatectomy: A Symptomatic and Urodynamic Analysis of 152 Patients. J. Urol. (1979), 121, 640-642.

Alan McNeill, S.: The role of alpha-blockers in the management of acute urinary retention caused by benign prostatic obstruction. Eur Urol. 2004 Mar;45(3)325-32

3 Alken, C. F.: Leitfaden der Urologie. 6. Auflage, Stuttgart, Thieme 1973

4 Alken/Walz: Urologie, S. 496-497, Chapman und Hall

5 Bailey, M J, Shearer, R.: The Role of Internal Uethrotomy in the Prevention of

Urethral Stricture following Transurethral Resection of Prostate. Br. J. Urol. (1979), 51, 28-31.

6 Ball, A. J., Powell, P. H.: Prostatectomy Trends in the Bristol Area.

Br. J. Urol. (1982), 54, 539-541.

7 Barba, M.: Flussdiagramm Diagnostik Benigne Prostatahyperplasie, Urologische Klinik und Poliklinik der Technischen Universität München, Klinikum rechts der Isar

8 Bartsch, G.; Müller, H. -J.; Oberholzer, M; Rohr, H. -P. Light microscopic stereological analysis of the normal human prostate and of benign prostatic hyperplasia. J Urol 122: 487-491

9 Bauer, H. W.; Sudhoff, F.; Dressler, St.: Benigne Prostatahyperplasie.

MMW (1989) Nr. 10, 229-234

10 Berger, A. P.; Wirtenberger, W.; Bektic, J.; Steiner, H.; Spranger, R.; Bartsch, G.; Horninger, W: Safer transurethral resection of the prostate: coagulating intermitting cutting reduces hemostatic complications.

J. Urol. 2004 Jan;171(1):289-91

11 Berry, S. J.; Coffey, D. S.; Walsh, P. C.; Ewing, L. L.: The development of human benign prostatic hyperplasiawith age. J. Urol. 132 (1984) 474

12 Blacklock, N. J.: Catheters and Urethral Strictures. Br. J. Urol. (1986), 58, 475-478.

13 Bracher, F.: Urologe (A) (1997) 36: 10-17, Springer Verlag 1997

14 Brandhauer, K., Madersbacher, H.: Früh- und Spätkomplikationen transurethraler Eingriffe an der Prostata. Urologe (1969), 8, 49-57

15 Britten, D.: Gefahren der operativen Behandlung des Prostataadenoms im terminalen Nierenversagen. Urologe A (1985), 24, 283-284.

16 Brown, G. A.; Sussman, D. O.: A current review of medical therapy for benign hyperplasia. J. Osteopath Assoc. 2004 Feb; 104(2Suppl 2):S 11-6

17 Bruskewitz, R. C., Larsen, E. H., Madsen, P. O.,Dorflinger, T.: 3-Year Followup of Urinary Symptoms After Transurethral Resection of the Prostate.J. Urol (1986), $136,613-615$

18 Chilton, C. P., Morgan, R. J., England, H. R., Paris, A. M. I., Blandy, J. P.: A Critical Evaluation of the Results of Transurethral Resection of the Prostate. Br. J. Urol. (1978), 50, 542-546.

19 Conrad, S.; Gonnermann, D.; Heinzer, H.; Kabalin, J. N.; Huland, H.: Transurethrale Lasertherapie der benignen Prostatahyperplasie.

Urologe (A) (1995) 34: 25-34, Springer Verlag 1995

20 Deliveliotis, C.; Liakouras, C.; Delis, A.; Skolarikos, A.; Varkarakis, J.; V.: Prostate operations: long-term effects on sexual and urinary

Protogerou, and quality of life. Comparison with an age-matched control population. Urol Res. 2004 Mar 31 
21 Fiedler, U., Rost, A., von Versen, L. H.: Vergleichende Statistik zur Komplikationsrate bei Enukleation und transurethraler Resektion des Prostataadenoms, Urologe A (1979)

22 Fowler, Ffloyd J., Wenneberg, John E., Timothy, Robert P., Barry, Michael J., Mulley, Albert G., Hanley, Daniel: Symptom Status and Quality of Life Following Prostatectomy. JAMA (1988), 259, 3018-3022.

23 Gravas, S.; Laguna, M. P.; De La Rosette, J. J.:Application of external microwave thermotherapy in urology: past, present, and future. J. Endourol. 2003 Oct;17(8): 659-66

24 Gurdal, M.; Tekin, A.; Yucebas, E.; Sengor, F.: Nd:YAG laser ablation plustransurethral resection for large prostates in high-risk patients. Urology. 2003 Nov;62(5):914-7.

25 Hartung, R.; Barba, M.: Instrumentelle Therapie der benignen Prostatahyperplasie.

Dt Ärztebl 2000; 97: A 989-997 (Heft 15)

26 Hartung, R., Mauermayer, W.: Die Harnröhrenstriktur nach transurethralen Eingriffen: Ursachen, Vorbeugung, Ergebnisse. Urologe A (1979), 18, 64-67.

27 Heimbach, D.; Müller, S. C.: Urologe (A) (1997) 36: 18-34, Springer Verlag 1997

28 Hellwig, J.; Pinkenburg, F.: Aktuelle Aspekte zur benignen Prostatahypertrophie;

MMW 134 (1992) Nr. 36, 565-568

29 Höfner,K.; Krah, H.; Tan, H. K.; Kuczyk, M.; Jonas, U.: Thermotherapie der benignen Prostatahyperplasie. Urologe (A) (1995) 34: 16-24, Springer Verlag 1995

30 Horninger, W.; Bartsch, G.: Hormonelle Therapie der benignen Prostatahyperplasie, Urologe [A] (1995) 34: 9-15

31 Jocham, D. und Müller, K.: Praxis der Urologie, Band II,Thieme Verlag, S. 216-242

32 Keuler, F.-U., Altwein, J. E.: Ist vor einer transurethralen oder offenen Prostataadenomektomie über erektile Impotenz aufzuklären? Urologe B (1991), 31, 104-107.

33 Kolozsy, Z., Csapò, Z.: Blasenhalsperforation infolge TURP. Z. Urol. Nephrol. (1983), 76, 65-73.

34 Laguna, M. P.; Alivizatos, G.; De La Rosette, J. J.: Interstitial laser coagulation teatment of benign prostaticHyperplasia. J. Endourol. 2003 Oct;17(8): 595-600

35 Lentz, Calvin H., Mebust, Winston K., Foret, John D., Melchior, Jerome: Urethral Strictures Following Prostatectomy: Review of 2223 Resections. J. Urol. (1977), 117,194-196.

36 Levin, Klas, Nyren, Olov, Pompeius, Rolf: Blood Loss, Tissue Weight and Operating Time in Transurethral Prostatectomy. Scand J. Urol. Nephrol. (1981), 15, 197200.

37 Lundhus, Eskild, Dorflinger, Moller-Madsen, Bjarne, Norgard, Jens P., Simonsen, Ole H., Stodkilde-Jorgensen, Hans, Olesen, S.: Significance of the Extent of Transurethral Prostatic Resection for Postoperative Complications. Scand. J. Urol. Nephrol: (1987), 21, 9-12.

38 Madersbacher, H., Marberger, H.: Zur Harnröhrenstriktur nach transurethralen Operationen. Urologe A (1971), 10, 66-67.

39 Malone, P. R., Cook, A., Edmonson, R., Gill, M. W., Shearer, R. J.: Prostatectomy: Patients' Perception and Long-term Follow-up. Br. J. Urol. (1988), 61, 234-238.

40 Matz, M., Zepniek, H.: Zur Problematik der Blasenhalsstrikturen nach TUR - Grenzen transurethraler Therapie. Z. Urol. Nephrol. (1984), 77, 329-333.

41 Meißner, Rosemarie, Thiel, U.: Transurethrale Zweiteingriffe am Blasenhals. Z. Urol. Nephrol. (1980), 73, 297-301.

42 Meyhoff, H. H., Hald, T.: Economy in Transurethral Prostatectomy. Scand J. Urol. Nephrol. (1985), 19, 17-20.

43 Meyhoff, H. H., Nordling, J., Hald, T.: Transurethral versus Transvesical Prostatectomy. Scand. J. Nephrol. (1985), 19, 85-91. 
Meyhoff, H. H., Nordling, J.: Long Term Results of Transurethral and Transvesical Prostatectomy. Scand. J. Urol. Nephrol. (1986), 20, 27-33.

Muschter, R.; Hofstetter, A.: Urologe (A) (1994) 33: 281-287, 1994

Naspro, R.; Freschi, M.; Salonia, A.; Guazzioni, G.; Di, V.; Scattoni, R. C.; Rigatti, P.; Montorsi, F.: Holmium laser enucleation versus transurethral resection of the prostrate. Are histological findigs comparable? J. Urol. 2004 Mar;171(3):1203-6.

Obrant, K. O.: Transurethral Electroresection of Prostatic Adenoma. Scand. J. Urol. Nephrol., 10, 26-32Occhiato, E. G.; Guarna, A.; Danza, G.; Serio, 48M: Selective non-steroidal inhibitors of 5alpha-reductase type 1. J. Steroid Biochem Mol Biol. 2004 Jan;88(1):1-16.

49 O’Sullivan, M.; Murphy, C.; Deasy, C.; Iohom, G.; Kiely, E. A.; Shorten, G.: Effects of transurethral resection of prostrate on the quality of patients with benign prostatic hyperplasia. J Am Coll Surg. 2004 Mar;198(3):394-403

Reid, G. F., Fitzpatrick, J. M., Worth, P. H. L.: The Treatment of Patients with Urinary Incontinence after Prostatectomy. Br. J. Urol. (1980), 52, 532-534.

51 Roger S. Kirby; Timothy J. Christmas: Benigne Prostata-Hyperplasie, 2. Ausgabe, Mosby-Wolfe (1997), S. 8, 15-23, 44-46, 59-88

Roos, Noralou P., Wenneberg, John E., Malenka, David J., Fisher, Elliott S., McPershon, Klim, Andersen, Tavs Folmer, Cohen, Marsha M., Ramsey, Ernest: Mortality and Reoperation after Open and Transurethral Resection of the Prostate for Benign Prostatic Hyperplasia. N. England J. Med. (1989), 320, 1120-1126.

54 Sachse, H., Tiefel, W., Sachse. L.: Ursachen und Vermeidung von Komplikationen bei transurethralen Eingriffen. Urologe A (1985), 24, 189-194.

55 Schreiter, F.: Plastisch-rekonstruktive Chirurgie in der Urologie; 1999 Thieme Verlag, S. 303-308

56 Schulze, H.: Benigne Prostatahyperplasie Urologe [A] (1997) 36: 1-2

57 Sheldon, Curtis A., Williams, Richard D., Fraley, Elwin E.: Incidental Karzinoma of the Prostate: A Review of the Literature and Critical Reappraisal of Classification. J. Urol. (1980), 124, 626-631.

58 Sikafi, Z., Butler, M. R., Lane, V., O’Flynn, J. D., Fitzpatrick, J. M.: Bladder Neck Contracture Following Prostatectomy. Br. J. Urol. (1985), 57, 308-310.

Singh, M., Tresidder, G. C., Blandy, J. P.: The Evaluation of Transurethral Resection for Benign Enlargement of the Prostate. Br. J. Urol. (1973), 45, 93-102.

Smith, P.; Rhodes, N. P.; Ke, Y.; Foster, C. S.: Relationship between upregulated oestrogen receptors and expression of growth factors in cultured, human, prostatic stromal cells exposed to estradiol or dihydrotestosterone. Prostrate Cancer Prostatic Dis. 2004;7(1):57-62

61 Talpur, A. N.; Hasan, A. T.; Sheikh, M. A.: Intraprostatic tissue infection in catheterised patients incomparison to controls. J Pak Med Assoc. 2004 Jan; 54(1):20-4

Tomamichel, G. R., Häuptle, Ch.: Die transurethrale Prostatektomie bei Prostatahyperplasie in hohem Alter. Schweiz. Rundschau Med. (1984), 73, 203207

63 Urologe (A): Veterans Administration Study Group, Veröffentlichung 1997/98/99

64 Vahlensieck, W.: Konservative Behandlung von Prostata-Adenomen. Urologe B (1973), 13, 176-177

65 Vahlensieck, W.: Miktionsstörungen bei Prostataerkrankungen. Fortschritte der Medizin (1970), 88, 2, 1183-1187

66 Varkarakis, J.; Bartsch, G.; Horninger, W.: Long-term morbidity and mortality of transurethral prostatectomy: a 10-year follow-up. Prostate. 2004 Feb 15;58(3): 248-51 
67 Vesey, S. G., Goble, N. M., Stower, M. J., Hammonds, J. C., Smith, P. J. B.: The Effects of Transurethral Prostatectomy on Serum Prostate Specific Antigen. Br. J. Urol. (1988), 62, 347-251.

68 Weisser, H.; Krieg, M.: Die benigne Prostatahyperplasie - das Ergebnis einer altersbedingten Entgleisung der Androgen-Estrogen-Balance? Urologe [A] (1997) 36: $3-9$ 